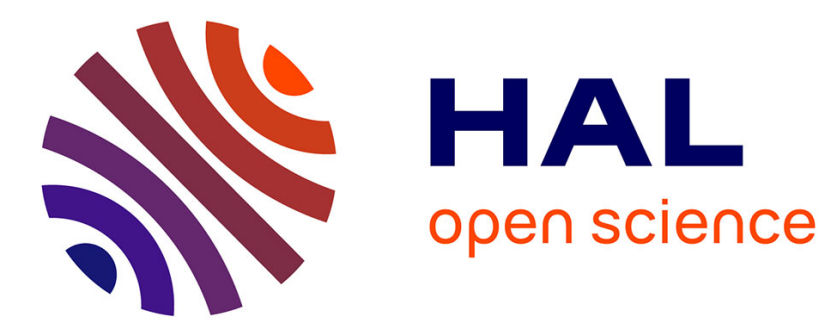

\title{
Compositional variations of the lunar crust: Results from radiative transfer modeling of central peak spectra
}

\author{
J. T. S. Cahill, P. G. Lucey, M. Wieczorek
}

\section{To cite this version:}

J. T. S. Cahill, P. G. Lucey, M. Wieczorek. Compositional variations of the lunar crust: Results from radiative transfer modeling of central peak spectra. Journal of Geophysical Research, 2009, 114 (E9), pp.E09001. 10.1029/2008JE003282 . hal-02458562

\section{HAL Id: hal-02458562 \\ https://hal.science/hal-02458562}

Submitted on 29 Jun 2020

HAL is a multi-disciplinary open access archive for the deposit and dissemination of scientific research documents, whether they are published or not. The documents may come from teaching and research institutions in France or abroad, or from public or private research centers.
L'archive ouverte pluridisciplinaire $\mathbf{H A L}$, est destinée au dépôt et à la diffusion de documents scientifiques de niveau recherche, publiés ou non, émanant des établissements d'enseignement et de recherche français ou étrangers, des laboratoires publics ou privés. 


\title{
Compositional variations of the lunar crust: Results from radiative transfer modeling of central peak spectra
}

\author{
J. T. S. Cahill, ${ }^{1}$ P. G. Lucey, ${ }^{1}$ and M. A. Wieczorek ${ }^{2}$ \\ Received 15 October 2008; revised 26 February 2009; accepted 1 May 2009; published 3 September 2009.
}

[1] We present model mineralogy of impact crater central peaks combined with crustal thickness and crater central peak depth of origin models to report multiple perspectives of lunar crustal composition with depth. Here we report the analyses of 55 impact crater central peaks and how their compositions directly relate to the lunar highlands sample suite. A radiative transfer model is used to analyze Clementine visible plus near-infrared spectra to place compositional constraints on these central peak materials. Central peaks analyzed are dominantly magnesian- and plagioclase-poor; strong compositional similarities to lunar Mg-suite materials are evident. Relative to crustal thickness estimates, central peak mineralogy becomes more plagioclase-rich as the crust thickens. Relative to the crust-mantle boundary, the origin of peaks with dominantly mafic mineralogy are confined to the lower crust and primarily within the South-Pole Aitken and Procellarum KREEP Terranes (PKT); additionally, central peaks with anorthositic mineralogy ( $>60$ vol \% plagioclase) are transported to the surface from all depths in the crustal column and confined to the Feldspathic Highlands Terrane (FHT). The discovery of mafic and magnesian materials, consistent with $\mathrm{Mg}$-suite rocks of the sample collection, in all lunar terranes suggests that the process and sources that give rise to these types of rocks is not unique to the PKT and not necessarily dependent on incompatible elements for formation. The identification of ferroan and magnesian anorthositic material near the crust-mantle boundary of the FHT is also inconsistent with an increasing mafic/feldspar ratio and $\mathrm{Mg}$ ' with depth in the crust.

Citation: Cahill, J. T. S., P. G. Lucey, and M. A. Wieczorek (2009), Compositional variations of the lunar crust: Results from radiative transfer modeling of central peak spectra, J. Geophys. Res., 114, E09001, doi:10.1029/2008JE003282.

\section{Introduction}

[2] Many lines of evidence suggest that the lunar crust varies in composition with depth. The first evidence to support this was the discovery of tiny flecks of feldspar within the first lunar soil sample collected (10084) [Smith et al., 1970; Wood et al., 1970]; these grains of feldspar were inferred to originate from the nearby highlands and suggested the lunar crust consisted predominantly of plagioclase-rich rocks. This discovery led Wood et al. [1970] to hypothesize that the Moon formed from a global magma ocean and the first compositional constituents to float to the surface and build a crust consisted of anorthite. Further examination of lunar rocks also revealed mafic, magnesian samples that added compositional complexity to our view of crustal composition and formation subsequent to anorthositic crust emplacement [Warner et al., 1976; Warren and Wasson, 1977].

[3] In order to better understand these complexities scientists looked to additional samples and data sets to

\footnotetext{
${ }^{1}$ Hawaii Institute of Geophysics and Planetology, University of Hawaii at Mānoa, Honolulu, Hawaii, USA.

${ }^{2}$ Institut de Physique du Globe de Paris, Saint-Maur, France.

Copyright 2009 by the American Geophysical Union. 0148-0227/09/2008JE003282\$09.00
}

analyze ever deeper lunar material. Ryder and Wood [1977] hypothesized that the "black-and-white" impact melt rocks of 15445 and 15455, associated with the Serenitatis and Imbrium impact basins, suggested that lunar crust consisted of three layers of systematically increasing mafic mineralogy with depth. Other sample studies, including those of Luna 24 regolith, suggested the crust showed lateral compositional heterogeneity [Warner et al., 1978]. Warren [1979] and James [1980] synthesized these complexities and hypothesized that they could be explained via intrusions of separate ultramafic partial melts from the mantle (i.e., $\mathrm{Mg}$-suite rocks) into a ferroan anorthosite (FAN) lunar crust formed via plagioclase flotation.

[4] Other scientists focused their research efforts on the deeply excavating exposures of impact craters and basins, using Earth-based telescopic and orbital remote sensing data sets. Spudis et al. [1984] and Spudis and Davis [1986] observed a systematic trend in composition with basin diameter which they interpreted to indicate vertical chemical structure within the crust. Spudis and Davis' [1986] analysis of several impact basins led to their hypothesis that the crust consisted of an upper crustal mixture of anorthositic gabbro overlying mafic noritic (e.g., norite, LKFM basalts, and potassium, rare earth element, and phosphorus (KREEP) bearing) basement rocks intruded sporadically by $\mathrm{Mg}$-suite lithologies. 
[5] Pieters [1986] focused on examination of telescopic spectra of large impact crater central peaks on the lunar nearside. Pieters' [1986] study detected significant compositional complexity in the crust, laterally and vertically. Tompkins and Pieters [1999] expanded upon Pieters' [1986] study, for the first time examining a global distribution of impact central peaks with ultraviolet and visible multispectral Clementine images. Tompkins and Pieters [1999] spectral analysis of 109 crater peaks showed an unprecedented amount of compositional heterogeneity in the crust, but yielded no clear vertical or lateral patterns in lithology. Building upon these findings, Wieczorek and Zuber [2001] combined quantitative geophysical model estimates of lunar crustal thickness with the compositional results of Tompkins and Pieters [1999] to detect distinct compositional differences between the upper and lower portion of the crust; the upper crust averaged $\sim 85$ vol $\%$ plagioclase compared to a more mafic $65 \mathrm{vol} \%$ plagioclase for the lower crust.

[6] Here we aim to build upon these studies combining quantitative spectral reflectance and crustal thickness algorithms to examine the stratigraphic composition of the lunar crust. Wieczorek and Zuber's [2001] model predicted that 17 craters of the Tompkins and Pieters [1999] data set sampled the lower crust of the Moon. In this study we specifically target craters that plausibly transport material from the deepest crust (and perhaps mantle) by using the lunar crust-mantle boundary as a point of reference when examining each crater peak. Our approach to modeling the crust is similar to that of Wieczorek and Zuber [2001] where we consider impact crater central peak origin relative to a single layered crustal thickness model. With this information we prioritize our selection of craters to survey for central peaks that plausibly excavated lower crust and/or mantle material. Out of the 55 impact crater central peaks reported here, approximately half are calculated to plausibly excavate material from within $5 \mathrm{~km}$ or below the crust-mantle interface. Tompkins and Pieters [1999] spectral interpretation approach of designating spectral classes for different rock types is then refined by analyzing combined Clementine visible (UVVIS) and near-infrared (NIR) reflectance spectra with a quantitative radiative transfer model based upon the work of Hapke [1981, 1993, 2001]. Similar versions of this model have been implemented and validated in the lunar and asteroid literature [Cahill and Lucey, 2007; Denevi et al., 2008; Lawrence and Lucey, 2007; Lucey, 2004; Lucey and Noble, 2008]. We demonstrate this method on the impact crater central peak Finsen which is a typical example of the crater sample examined here. Compositionally, Tompkins and Pieters [1999] observed an exceptional amount of spectral variability in Finsen including some of the only central peak spectra interpreted to be orthopyroxene-rich (other craters include Bullialdus, Birkeland, Bhabha, Lyman, and White). It has been hypothesized by some that these orthopyroxene-rich peaks may indicate a compositional transition to lower crustal material [Wieczorek and Zuber, 2001].

[7] Our crater sample shows compositional complexity similar to that reported by Tompkins and Pieters [1999]; however, our combined estimates of crustal thickness, crater depth of origin, and composition for these peaks have allowed us to identify trends in composition vertically and horizontally. Our results suggest a more mafic crust than reported by Tompkins and Pieters [1999]. The most mafic of these lithologies are largely confined to within $40 \mathrm{~km}$ of the crust-mantle boundary and in the South-Pole Aitken (SPA) and Procellarum KREEP Terranes (PKT). Anorthositic peaks are largely confined to the Feldspathic Highlands Terrane (FHT), but are found at all levels of the crustal column. Despite these findings peaks with an average composition indicative of anorthosite are rarely detected. Previous studies show that anorthosite is abundant in peak rings, but these are not examined here [Hawke et al., 1991; Hawke et al., 1993; Hawke et al., 2003; Spudis et al., 1984]. The majority of peaks in this study show remarkable compositional similarity to $\mathrm{Mg}$-suite lithologies in the lunar sample collection. The likely reason for this is our sampling of craters which is dominated by models that suggest their peaks originated within lower crust or mantle.

\section{Approach}

\subsection{Modeling Crustal Thickness}

[8] In order to select craters to analyze and examine any correlations in composition they may have with depth we first need to define the thickness of the crust globally. The models presented here are based upon the models of Wieczorek and Phillips [1998] and Wieczorek et al. [2006]. First, the gravity field that results from surface topography is computed (i.e., the Bouguer correction). This contribution is subtracted from the observed free air gravity field of the body, resulting in the Bouguer anomaly which is interpreted as relief along a subsurface density interface. These models assume that the crust is uniform in density (excluding a thin veneer of mare basalts in some areas) but do not assume that the Moon is isostatically compensated. A crustal thickness of $45 \mathrm{~km}$ at the Apollo 12 and 14 sites serves as our modeling anchor points [Wieczorek et al., 2006]. This thickness is consistent with recent seismic inversions which suggest that the crustal thickness at these two sites is probably considerably thinner than the $65 \mathrm{~km}$ suggested by Toksöz et al. [1972]. Current thickness estimates of these sites include $45 \pm 5 \mathrm{~km}$ [Khan et al., 2000], $38 \pm 8 \mathrm{~km}$ [Khan and Mosegaard, 2002], and $30 \pm 2.5 \mathrm{~km}$ [Lognonne et al., 2003].

[9] Our first model, model 1, is a canonical model in which the lunar gravity field is assumed to be solely the result of surface topography, a thin veneer of dense mare basalts, and relief along the crust-mantle interface. For this model the gravitational attraction of the mare basalts within the nearside mascon basins was taken into account using the mare thickness model of Solomon and Head [1980] modified by the maximum thickness constraints of Williams and Zuber [1998]. A density of 2900 and $3300 \mathrm{~kg} \mathrm{~m}^{-3}$ was assumed for the crust and mare basalts, respectively. For this model, a density of $3320 \mathrm{~kg} \mathrm{~m}^{-3}$ was assumed for the upper mantle.

[10] Model 2 has one substantial difference from model 1. In model 2 we allow for the possibility that the degree-1 shape of the Moon might not be the result of crustal thickness variations (i.e., the $1.9 \mathrm{~km}$ center-of-mass/centerof-figure offset) but might instead be a result of lateral variations in density of the crust and/or mantle. In particular, the spherical harmonic degree-1 Bouguer anomaly terms were set to zero before inverting for the crustal thickness. 


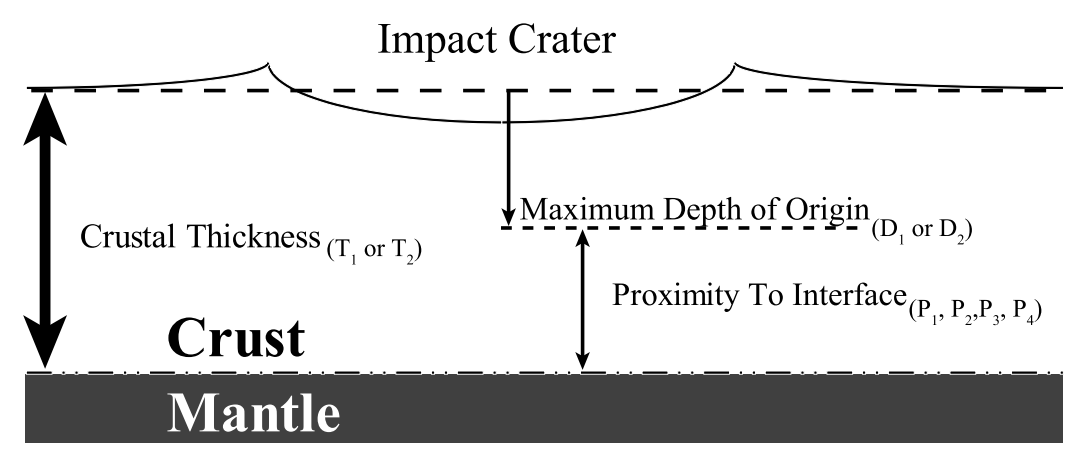

Figure 1. For each crater the proximity to the lunar crust-mantle boundary was calculated by subtracting the depth of origin $(D)$ from the crustal thickness $(T)$. Here proximity to the crust-mantle boundary $(P)$ via the maximum depth of origin is illustrated.

[11] The resulting average crustal thicknesses for models 1 and 2 are 53 and $43 \mathrm{~km}$. The uncertainty of our crustal thickness maps is difficult to quantify as this depends upon our choice of the crustal and mantle densities, which are, a priori, not well known, as well as the uncertainty in the gravity model, which is poorly constrained over the farside hemisphere. Given that our models are also anchored by the Apollo seismic data, and the most recent inversion results differ by about $10 \mathrm{~km}$, it is probably prudent to use an uncertainty of at least $\pm 5 \mathrm{~km}$ for the absolute crustal thickness at any locale on the Moon.

[12] Both model 1 and 2 are used to determine a sample of potential mantle candidate peaks to examine here. Both models are valid scientific estimates of crustal thickness. However, in this study we simplify and focus on model 1 but recognize that aspects of each model are plausibly occurring in the lunar crust. Figures $\mathrm{S} 1-\mathrm{S} 4$ detailing aspects of model 2 crustal thickness estimates and 0.1D estimates of peak depth of origin are located in the auxiliary material. ${ }^{1}$

\subsection{Modeling Peak Depth of Origin}

[13] Peak depth of origin is difficult to estimate owing to the number of variables that influence the calculation. Each impact crater was created with a unique set of variables that characterize the initial impactor, its path, as well as the target material that ultimately influence the depth a peak will originate. However, studies of both impact theory and terrestrial craters have provided some benchmarks to make estimates of peak origin. Previous estimates of crater depth of excavation, which is referring to the depth of origin of crater ejecta, are estimated to be 0.1 to 0.2 times the diameter, D, of complex craters [Croft, 1980; Dence, 1968; Melosh, 1989; O'Keefe and Ahrens, 1993; Roddy, 1977]. However, another estimate to consider is the depth of melting. Cintala and Grieve [1998] suggest that the minimum depth of origin for a central peak coincides with the maximum depth of melting, and this origin is a function of crater diameter. The resulting depth of melting incurred by the crust follows an estimate of $0.109 \mathrm{D}^{1.08}$, where $\mathrm{D}$ is the final rim diameter of the crater in kilometers. This approx-

${ }^{1}$ Auxiliary materials are available in the HTML. doi:10.1029/ 2008JE003282. imation method falls somewhere in between $0.1 \mathrm{D}$ to $0.2 \mathrm{D}$ depending on the diameter of the crater being examined.

[14] Here, we consider both approximations of peak depth of origin; one estimating a depth of origin at $0.1 \mathrm{D}$ and the other at $0.109 \mathrm{D}^{1.08}$. The concept for estimating peak depth of origin is that the peak must originate from below the melt, so that the Cintala and Grieve [1998] estimates for depth of melting provide a lower limit or the maximum possible depth of origin that can differ substantially from $0.1 \mathrm{D}$ for large craters. We use both estimates to determine our sampling of craters to examine, but neither is shown to have a higher correlation with composition. For this reason here we simplify and focus on the method of Cintala and Grieve [1998]. Impact crater diameter and location are determined from the online database of J. McDowell (available at http://host.planet4589.org/astro/lunar/). With this information craters were evaluated for discernable peaks before they were examined spectrally.

\subsection{Determination of Central Peak Origin in the Crust}

[15] Once we have constructed our crustal thickness models and estimated peak depth of origin we combine them to select craters of interest and determine vertical and lateral correlations with composition. Two methods of relating crater peak position and origin with composition are used. First, composition relative to the crustal thickness in the vicinity of each peak is examined to determine if composition is correlated with the overall thickness of the lunar crust. Second, we also examine where peak material originated within the crust relative to the crust-mantle boundary. This is examined in two ways. One estimate is calculated by determining the difference between the crustal thickness and peak excavation depth (Figure 1). This is expressed by the equation

$$
P=T-D
$$

where $P$ is proximity to the crust-mantle boundary, $T$ is crustal thickness estimates for model 1 or model 2, respectively, and $D$ is the depth of origin using estimates for the maximum depth of melting $\left(D_{1}\right)$ or maximum depth of excavation $\left(D_{2}\right)$, respectively. For peaks where $P$ is negative, crater peaks plausibly expose mantle material and for craters where $P$ is positive peaks are modeled as having no chance of exhuming lunar mantle material. 

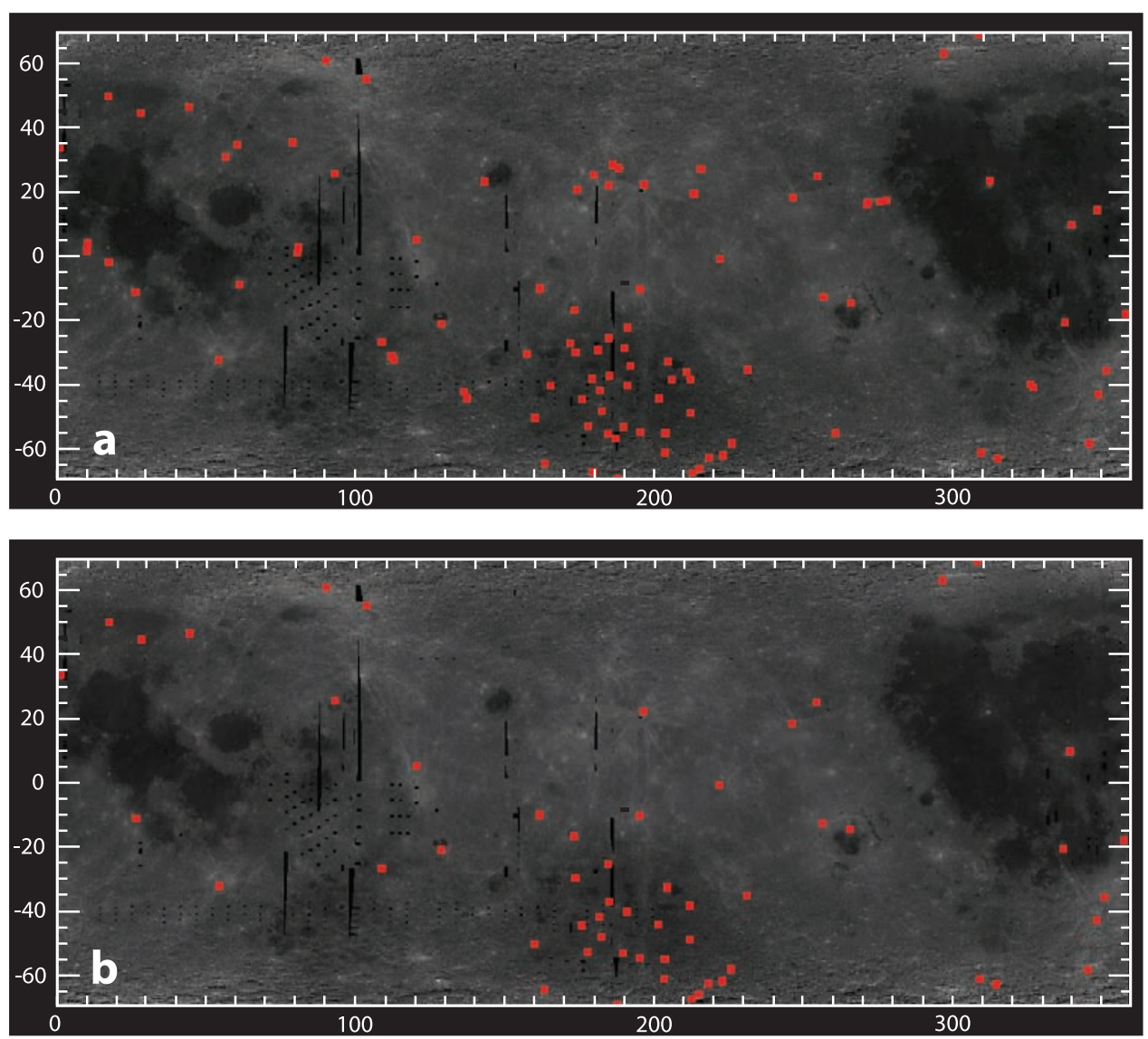

Figure 2. Location map of the impact crater central peaks examined in this study plotted on a Clementine $750 \mathrm{~nm}$ simple cylindrical image of the global lunar surface $\left(1 \mathrm{~km} \mathrm{pixel}^{-1}\right)$. (a) Red boxes denote the impact crater central peaks that were considered for compositional modeling. (b) Red boxes denote the impact crater central peaks that have immature material and were analyzed in this study.

[16] For our second estimate, we examine where peak material originates relative to the current state of the crustal column. To do this, we scale $P$ to the crustal thickness under that crater giving us knowledge of peak origin vertically relative to crustal thickness. This is expressed by the equation

$$
R=(T-D) / T
$$

where $R$ is a dimensionless quantity less than 1 that estimates the original position of central peaks in the context of the crustal column. For peaks where $R$ is positive, material originated within the crust (e.g., 0 to 1 ); and for peaks where $R$ is negative (e.g., $<0)$, material originated from the lunar mantle.

[17] Crater peaks are prioritized for analysis using the parameter $P$. Crater central peaks modeled as plausibly originating in the lunar mantle, or at least lower crust, are given first priority for analysis. From this list we evaluate impact craters with high-resolution Clementine data $\left(100 \mathrm{~m} \mathrm{pixel}^{-1}\right)$ to determine if a peak is present and that immature material (i.e., a value $>0.3$ using the optical maturity parameter (OMAT) of Lucey et al. [2000]) is available for analysis. This yields 28 central peaks we examine with material estimated to plausibly originate in or near the mantle. An additional 27 central peaks selected at random are examined for which no models predict the excavation of mantle rocks. This yields a total of 55 peaks and their compositions reported here out of the $\sim 100$ craters evaluated for a central peak and immature material based upon the optical maturity parameter of Lucey et al. [2000] (Figure 2).

\subsection{Spectral Analysis Approach}

[18] Crater central peaks are analyzed by comparing Clementine reflectance spectra to radiative transfer modeled spectra. The radiative transfer theory of Hapke [1981, 1993, 2001], mineral optical constant data of Lucey [1998] and iron optical constant data of Paquin [1995] are used in this model. Similar implementations of the model used here are reported by Clark et al. [2001], Cahill and Lucey [2007], and explained in detail by Lawrence and Lucey [2007]. In general, the model uses the optical constants (real, $n$, and complex indices, $k$, of refraction) of minerals to calculate single scattering albedo (the probability a photon will survive an encounter with a material) for each component at a specified particle size, maturity, and mineral chemistry. Single scattering albedo of each mineral component is added linearly, weighted by abundance, and converted to reflectance. Mineral modes used for this study span a plagioclase-olivine-orthopyroxene-clinopyroxene system at 
Table 1. Summary of Near-Infrared Correction Factors

\begin{tabular}{ccc}
\hline Spectra Band $(\mathrm{nm})$ & Gain & Offset \\
\hline 1100 & 0.87 & 0.0246 \\
1250 & 0.854 & 0.0316 \\
1500 & 0.792 & 0.0514 \\
2000 & 0.742 & 0.068 \\
\hline
\end{tabular}

5 vol \% intervals (17,710 modal combinations). Model spectra are computed and compared to Clementine spectra as a function of $\mathrm{Mg}$ number $\left(\mathrm{Mg}{ }^{\prime}=\right.$ molar $\mathrm{Mg} /(\mathrm{Mg}+\mathrm{Fe}) \times$ 100) ranging from 50 to 95 in increments of 5.

[19] We account for space weathering by using the optical maturity method of Lucey et al. [2000] and compute our models on the basis of the full range of immature compositions. Lucey et al.'s [2000] OMAT quantifies optical maturity combining the reflectance and spectral contrast of each spectrum in a manner that is largely insensitive to composition. At $1 \mathrm{~km}$ spatial resolution the Moon ranges from 0.2 (highly mature) to 0.5 (immature) in this parameter. Here we compute models to cover 46 levels of maturity from 0.275 to 0.5 OMAT in increments of 0.005 , which covers the full range of immature compositions on the surface of the Moon.

[20] Cahill and Lucey [2007] demonstrate that several models can have the same relative reflectance shape but very different absolute reflectance values. So, here the model with the most similar relative reflectance spectral fit and estimated $\mathrm{FeO}$ (which is a function of absolute reflectance) to that of each Clementine spectrum is chosen as a match. Clementine estimated $\mathrm{FeO}$ is determined via the method of Lawrence et al. [2002] and model FeO is determined stoichiometrically for each model mineralogy. Using $\mathrm{FeO}$ as a constraint exposes the method to errors due to the influence of the local slope relative to the Sun on the derivation of $\mathrm{FeO}$, so our uncertainties in estimating plagioclase content in particular are increased relative to a data set without this artifact. The relative error for individual minerals, $\mathrm{Mg}$ ', and $\mathrm{FeO}$ is conservatively $\pm 10-15 \%$, \pm 8 units, and $1-2 \mathrm{wt} \%$, respectively [Denevi et al., 2008; Lucey, 2004].

[21] The data analyzed here differ from Lucey [2004] and Cahill and Lucey [2007] by including both Clementine UVVIS and NIR data (e.g., eight wavelengths including $0.75,0.9,0.95,1.0,1.1,1.25,1.5$, and $2.0 \mu \mathrm{m})$ to enable better mineralogical interpretations. Both data sets are examined at a spatial resolution of $100 \mathrm{~m}$. Clementine near-infrared spectra are calibrated to Earth-based telescopic spectra collected of various locations on the lunar nearside. Documentation for these correction procedures and their results are posted on the USGS Web site (http://astrogeology. usgs.gov/Projects/ClementineNIR/) courtesy of B. W. Denevi and P. G. Lucey (personal communication, 2007). Spectra gain and offset corrections per near-infrared spectral band are reported in Table 1.

\section{Results}

[22] Our results are reported in several sections, each section gradually adds additional perspectives to our overall view of the lunar crust. We first illustrate our method of spectral analysis by reporting compositional and crustal thickness estimates on an example central peak. We then place all the peaks analyzed into the perspective of the lunar sample suite for compositional and petrologic context. Finally, we add "depth" to this petrologic context by placing our compositional results into several perspectives of estimated lunar crustal thickness and central peak point of origin in the crust.

\subsection{Analysis of Finsen Central Peak}

[23] Here we illustrate our analytical method applied to the impact crater Finsen as an example (Figure 3 ). Finsen is located within SPA at $42^{\circ} \mathrm{S}$ and $177.4^{\circ} \mathrm{W}$ and has a diameter of $72 \mathrm{~km}$. We estimate the local lunar crust in this area is between 5 and $16 \mathrm{~km}$ ( $T_{1}$ and $T_{2}$, respectively) in thickness and Finsen likely transported material from 7 to $11 \mathrm{~km}$ of depth. Finsen peak is also modeled to originate from $5 \mathrm{~km}$ above or $5 \mathrm{~km}$ below the lunar crust-mantle boundary $\left(P_{1}\right.$ and $P_{2}$, respectively; Table 2 ). The inferred proximity to the crust-mantle boundary makes Finsen a typical example of the deepest originating peaks we analyze here.

[24] Our derived compositions of Finsen central peak spectra are more mafic than previously reported by Tompkins and Pieters [1999] (Figures 4 and 5). Mineral maps of Finsen show that olivine and plagioclase abundances on average are low (9.4\% and $25.4 \%$, respectively), while the average abundances of orthopyroxene and clinopyroxene are higher (32.7\% and 32.5\%, respectively; Figure 5). On the lunar rock type classification scheme of Stöfler et al. [1980] Finsen's average lithology is a gabbroic norite; however, other lithologies present include norite, noritic gabbro,

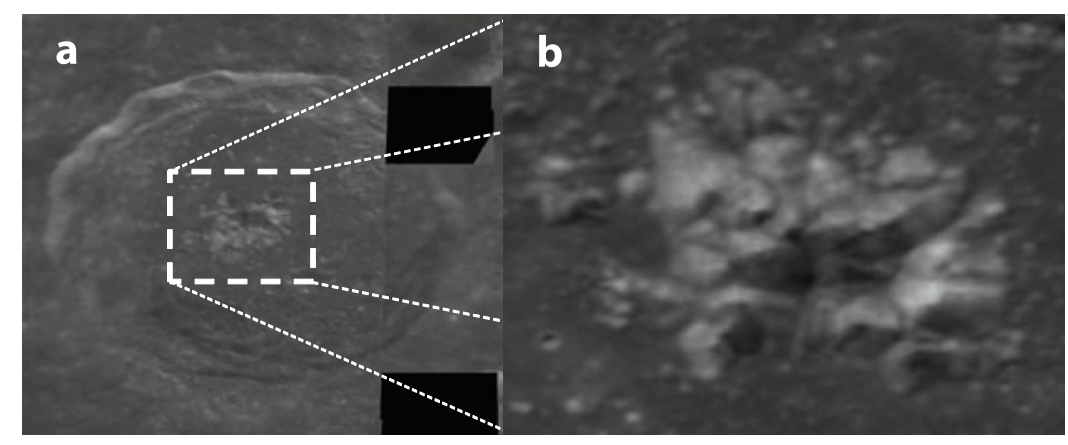

Figure 3. (a) Finsen crater is $72 \mathrm{~km}$ in diameter, and we estimate that it overlays crust that is $5-16 \mathrm{~km}$ in thickness. Black areas are void of Clementine data. (b) Finsen central peak is estimated to have exhumed material from between 7 and $11 \mathrm{~km}$ of depth. 
Table 2. Impact Crater Characteristics, Estimated Depth of Origin, and Crustal Thickness Values

\begin{tabular}{|c|c|c|c|c|c|c|c|c|c|c|c|c|c|c|c|}
\hline $\begin{array}{l}\text { Crater } \\
\text { Name }\end{array}$ & Diameter & $\begin{array}{l}\text { Latitude } \\
\text { (deg) }\end{array}$ & $\begin{array}{c}\text { Longitude } \\
\text { (deg) }\end{array}$ & $T_{1}$ & $T_{2}$ & $D_{1}$ & $D_{2}$ & $P_{1}{ }^{\mathrm{a}}$ & $P_{2}{ }^{\mathrm{b}}$ & $P_{3}{ }^{\mathrm{c}}$ & $P_{4}{ }^{\mathrm{d}}$ & $R_{1}^{\mathrm{e}}$ & $R_{2}{ }^{\mathrm{f}}$ & $R_{3}{ }^{\mathrm{g}}$ & $R_{4}{ }^{\mathrm{h}}$ \\
\hline Aitken & 135 & -16.8 & 173.4 & 41.0 & 26.4 & 22.2 & 13.5 & 18.8 & 4.2 & 27.5 & 12.9 & 0.5 & 0.2 & 0.7 & 0.5 \\
\hline Alder & 77 & -48.6 & -177.4 & 17.1 & 6.7 & 12.1 & 7.7 & 5.0 & -5.3 & 9.4 & -1.0 & 0.3 & -0.8 & 0.5 & -0.1 \\
\hline Antoniadi & 143 & -69.7 & -172.0 & 16.2 & 9.3 & 23.6 & 14.3 & -7.4 & -14.4 & 1.9 & -5.0 & -0.5 & -1.5 & 0.1 & -0.5 \\
\hline Aristillus & 55 & 33.9 & 1.2 & 30.8 & 31.8 & 8.4 & 5.5 & 22.4 & 23.4 & 25.3 & 26.3 & 0.7 & 0.7 & 0.8 & 0.8 \\
\hline Aristoteles & 87 & 50.2 & 17.4 & 29.6 & 28.9 & 13.8 & 8.7 & 15.8 & 15.2 & 20.9 & 20.2 & 0.5 & 0.5 & 0.7 & 0.7 \\
\hline Arzachel & 96 & -18.2 & -1.9 & 38.8 & 41.7 & 15.3 & 9.6 & 23.5 & 26.4 & 29.2 & 32.1 & 0.6 & 0.6 & 0.8 & 0.8 \\
\hline Atlas & 87 & 46.7 & 44.4 & 33.7 & 32.9 & 13.8 & 8.7 & 20.0 & 19.1 & 25.0 & 24.2 & 0.6 & 0.6 & 0.7 & 0.7 \\
\hline Bel'kovich & 214 & 61.1 & 90.2 & 36.0 & 30.0 & 36.6 & 21.4 & -0.6 & -6.6 & 14.6 & 8.6 & 0.0 & -0.2 & 0.4 & 0.3 \\
\hline Berkner & 86 & 25.2 & -105.2 & 50.6 & 36.5 & 13.6 & 8.6 & 36.9 & 22.9 & 42.0 & 27.9 & 0.7 & 0.6 & 0.8 & 0.8 \\
\hline Bettinus & 71 & -63.4 & -44.8 & 40.2 & 36.8 & 11.1 & 7.1 & 29.1 & 25.7 & 33.1 & 29.7 & 0.7 & 0.7 & 0.8 & 0.8 \\
\hline Bhabha & 64 & -55.1 & -164.5 & 15.5 & 5.9 & 9.9 & 6.4 & 5.6 & -4.0 & 9.1 & -0.5 & 0.4 & -0.7 & 0.6 & -0.1 \\
\hline Birkeland & 82 & -30.2 & 173.9 & 22.9 & 10.9 & 12.9 & 8.2 & 10.0 & -2.0 & 14.7 & 2.7 & 0.4 & -0.2 & 0.6 & 0.2 \\
\hline Borman & 50 & -38.8 & -147.7 & 16.0 & 5.2 & 7.6 & 5.0 & 8.4 & -2.4 & 11.0 & 0.2 & 0.5 & -0.5 & 0.7 & 0.0 \\
\hline Bose & 91 & -53.5 & -170.0 & 16.2 & 6.4 & 14.5 & 9.1 & 1.8 & -8.0 & 7.1 & -2.7 & 0.1 & -1.3 & 0.4 & -0.4 \\
\hline Boyle & 57 & -53.1 & 178.1 & 13.9 & 4.9 & 8.7 & 5.7 & 5.2 & -3.8 & 8.2 & -0.8 & 0.4 & -0.8 & 0.6 & -0.2 \\
\hline Bullialdus & 60 & -20.7 & -22.2 & 25.0 & 26.6 & 9.2 & 6.0 & 15.8 & 17.4 & 19.0 & 20.6 & 0.6 & 0.7 & 0.8 & 0.8 \\
\hline Burg & 39 & 45.0 & 28.2 & 32.7 & 32.6 & 5.8 & 3.9 & 26.9 & 26.9 & 28.8 & 28.7 & 0.8 & 0.8 & 0.9 & 0.9 \\
\hline Carpenter & 59 & 69.4 & -50.9 & 38.5 & 31.3 & 9.0 & 5.9 & 29.4 & 22.2 & 32.6 & 25.4 & 0.8 & 0.7 & 0.8 & 0.8 \\
\hline Clavius & 245 & -58.8 & -14.1 & 39.3 & 38.3 & 42.4 & 24.5 & -3.0 & -4.1 & 14.8 & 13.8 & -0.1 & -0.1 & 0.4 & 0.4 \\
\hline Compton & 162 & 55.3 & 103.8 & 33.0 & 26.6 & 27.1 & 16.2 & 5.9 & -0.5 & 16.8 & 10.4 & 0.2 & 0.0 & 0.5 & 0.4 \\
\hline Copernicus & 93 & 9.7 & -20.1 & 33.3 & 34.2 & 14.8 & 9.3 & 18.5 & 19.3 & 24.0 & 24.9 & 0.6 & 0.6 & 0.7 & 0.7 \\
\hline Crommelin & 94 & -68.1 & -146.9 & 18.5 & 10.9 & 15.0 & 9.4 & 3.5 & -4.1 & 9.1 & 1.5 & 0.2 & -0.4 & 0.5 & 0.1 \\
\hline Crommelin $\mathrm{C}$ & 44 & -66.4 & -144.8 & 16.1 & 8.6 & 6.6 & 4.4 & 9.6 & 2.0 & 11.7 & 4.2 & 0.6 & 0.2 & 0.7 & 0.5 \\
\hline Crookes & 49 & -10.3 & -164.5 & 78.1 & 56.9 & 7.4 & 4.9 & 70.7 & 49.5 & 73.2 & 52.0 & 0.9 & 0.9 & 0.9 & 0.9 \\
\hline Davisson & 87 & -37.5 & -174.6 & 15.9 & 4.7 & 13.8 & 8.7 & 2.1 & -9.1 & 7.2 & -4.0 & 0.1 & -1.9 & 0.5 & -0.9 \\
\hline Dryden & 51 & -33.0 & -155.2 & 21.6 & 9.0 & 7.7 & 5.1 & 13.9 & 1.3 & 16.5 & 3.9 & 0.6 & 0.1 & 0.8 & 0.4 \\
\hline Eijkman & 54 & -63.1 & -141.5 & 15.9 & 7.9 & 8.2 & 5.4 & 7.7 & -0.3 & 10.5 & 2.5 & 0.5 & 0.0 & 0.7 & 0.3 \\
\hline Eijkman D & 25 & -62.3 & -136.9 & 16.3 & 8.3 & 3.6 & 2.5 & 12.8 & 4.8 & 13.8 & 5.8 & 0.8 & 0.6 & 0.8 & 0.7 \\
\hline Finsen & 72 & -42.0 & -177.9 & 16.3 & 5.4 & 11.2 & 7.2 & 5.1 & -5.8 & 9.1 & -1.8 & 0.3 & -1.1 & 0.6 & -0.3 \\
\hline Fizeau & 111 & -58.6 & -133.9 & 19.0 & 10.4 & 18.0 & 11.1 & 1.0 & -7.5 & 7.9 & -0.7 & 0.1 & -0.7 & 0.4 & -0.1 \\
\hline Grissom M & 38 & -49.1 & -147.7 & 18.1 & 7.5 & 5.6 & 3.8 & 12.4 & 1.9 & 14.3 & 3.7 & 0.7 & 0.3 & 0.8 & 0.5 \\
\hline Hopmann & 88 & -50.8 & 160.3 & 18.8 & 10.3 & 14.0 & 8.8 & 4.9 & -3.7 & 10.0 & 1.5 & 0.3 & -0.4 & 0.5 & 0.1 \\
\hline Jackson & 71 & 22.4 & -163.1 & 72.0 & 52.1 & 11.1 & 7.1 & 61.0 & 41.1 & 64.9 & 45.0 & 0.8 & 0.8 & 0.9 & 0.9 \\
\hline Joliot & 164 & 25.8 & 93.1 & 38.5 & 34.4 & 27.4 & 16.4 & 11.0 & 7.0 & 22.1 & 18.0 & 0.3 & 0.2 & 0.6 & 0.5 \\
\hline Keeler & 160 & -10.2 & 161.9 & 47.2 & 32.8 & 26.7 & 16.0 & 20.5 & 6.1 & 31.2 & 16.8 & 0.4 & 0.2 & 0.7 & 0.5 \\
\hline King & 76 & 5.0 & 120.5 & 50.0 & 41.3 & 11.9 & 7.6 & 38.1 & 29.4 & 42.4 & 33.7 & 0.8 & 0.7 & 0.8 & 0.8 \\
\hline Langmuir & 91 & -35.7 & -128.4 & 56.0 & 41.5 & 14.5 & 9.1 & 41.5 & 27.1 & 46.9 & 32.4 & 0.7 & 0.7 & 0.8 & 0.8 \\
\hline Lemaitre $\mathrm{S}$ & 34 & -61.6 & -156.3 & 16.2 & 7.5 & 5.0 & 3.4 & 11.3 & 2.5 & 12.8 & 4.1 & 0.7 & 0.3 & 0.8 & 0.5 \\
\hline Lowell & 66 & -12.9 & -103.1 & 63.7 & 48.5 & 10.2 & 6.6 & 53.5 & 38.2 & 57.1 & 41.9 & 0.8 & 0.8 & 0.9 & 0.9 \\
\hline Lyman & 84 & -64.8 & 163.6 & 18.0 & 10.9 & 13.3 & 8.4 & 4.7 & -2.4 & 9.6 & 2.5 & 0.3 & -0.2 & 0.5 & 0.2 \\
\hline Maksutov & 83 & -40.5 & -168.7 & 17.3 & 5.9 & 13.1 & 8.3 & 4.2 & -7.2 & 9.0 & -2.4 & 0.2 & -1.2 & 0.5 & -0.4 \\
\hline Maunder & 55 & -14.6 & -93.8 & 30.6 & 21.7 & 8.4 & 5.5 & 22.2 & 13.4 & 25.1 & 16.2 & 0.7 & 0.6 & 0.8 & 0.7 \\
\hline $\mathrm{Ohm}$ & 64 & 18.4 & -113.5 & 58.7 & 42.7 & 9.9 & 6.4 & 48.8 & 32.8 & 52.3 & 36.3 & 0.8 & 0.8 & 0.9 & 0.9 \\
\hline Orlov & 81 & -25.7 & -175.0 & 27.2 & 13.8 & 12.8 & 8.1 & 14.4 & 1.0 & 19.1 & 5.7 & 0.5 & 0.1 & 0.7 & 0.4 \\
\hline Pythagoras & 142 & 63.5 & -63.0 & 37.4 & 29.7 & 23.5 & 14.2 & 13.9 & 6.2 & 23.2 & 15.5 & 0.4 & 0.2 & 0.6 & 0.5 \\
\hline Scaliger & 84 & -27.1 & 108.9 & 41.8 & 36.6 & 13.3 & 8.4 & 28.5 & 23.3 & 33.4 & 28.2 & 0.7 & 0.6 & 0.8 & 0.8 \\
\hline Stevinus & 74 & -32.5 & 54.2 & 42.9 & 44.5 & 11.6 & 7.4 & 31.3 & 33.0 & 35.5 & 37.1 & 0.7 & 0.7 & 0.8 & 0.8 \\
\hline Stoney & 45 & -55.3 & -156.1 & 13.6 & 4.4 & 6.7 & 4.5 & 6.8 & -2.4 & 9.1 & -0.1 & 0.5 & -0.5 & 0.7 & 0.0 \\
\hline Theophilus & 110 & -11.4 & 26.4 & 29.2 & 33.6 & 17.8 & 11.0 & 11.4 & 15.8 & 18.2 & 22.6 & 0.4 & 0.5 & 0.6 & 0.7 \\
\hline Tsiolkovsky & 185 & -21.2 & 128.9 & 49.2 & 40.1 & 31.2 & 18.5 & 18.0 & 8.8 & 30.7 & 21.6 & 0.4 & 0.2 & 0.6 & 0.5 \\
\hline Tycho & 102 & -43.4 & -11.1 & 40.9 & 41.5 & 16.4 & 10.2 & 24.5 & 25.1 & 30.7 & 31.3 & 0.6 & 0.6 & 0.8 & 0.8 \\
\hline Vavilov & 98 & -0.8 & -137.9 & 76.5 & 56.6 & 15.7 & 9.8 & 60.8 & 40.9 & 66.7 & 46.8 & 0.8 & 0.7 & 0.9 & 0.8 \\
\hline Von Karman & 180 & -44.8 & 175.9 & 17.1 & 6.9 & 30.3 & 18.0 & -13.3 & -23.5 & -0.9 & -11.1 & -0.8 & -3.4 & -0.1 & -1.6 \\
\hline White & 39 & -44.6 & -158.3 & 20.1 & 8.5 & 5.8 & 3.9 & 14.3 & 2.7 & 16.2 & 4.6 & 0.7 & 0.3 & 0.8 & 0.5 \\
\hline Zucchius & 64 & -61.4 & -50.3 & 40.0 & 36.3 & 9.9 & 6.4 & 30.1 & 26.4 & 33.6 & 29.9 & 0.8 & 0.7 & 0.8 & 0.8 \\
\hline
\end{tabular}

pyroxenite, and olivine-bearing gabbronorite. The average $\mathrm{Mg}$ ' for Finsen central peak is 63.7, but the range of $\mathrm{Mg}$ ' is $40-75$ indicating the presence of both ferroan and magnesian lithologies. Mean $\mathrm{FeO}$ determined from Clementine spectra is $14 \mathrm{wt} \%$ and ranges from 10 to $22 \mathrm{wt} \%$.

\subsection{Central Peak Composition Relative to Lunar Samples}

[25] All other central peaks are analyzed in the same way as described for Finsen (Tables 2-3). Here we establish the modeled composition of each peak relative to the known 

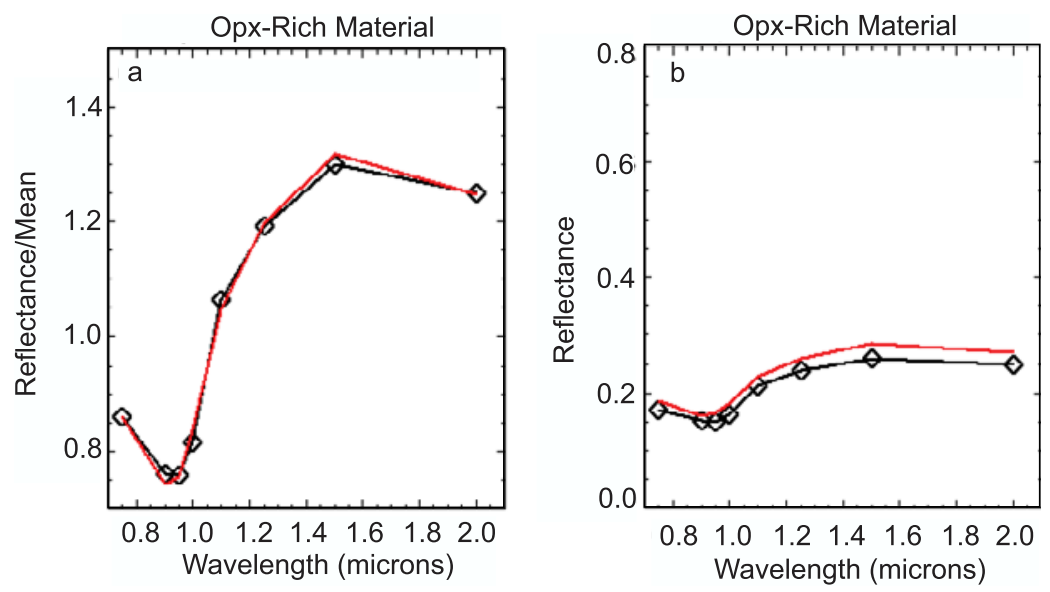

Figure 4. Representative Clementine and model visible (VIS) and near-infrared (NIR) spectra in (a) relative and (b) absolute reflectance formats.

compositions of lunar highlands samples. Models of central peak spectra show a large diversity of average lithologies but most of them are dominantly mafic (Figure 6). Peaks with mafic model mineralogy also show many similarities to olivine-bearing gabbronorite $\mathrm{Mg}$-suite rocks of the lunar sample collection. However, peak pyroxene abundances show more diversity with orthopyroxene-rich gabbroic norite and clinopyroxene-rich noritic gabbro lithologies both being present. Several peaks modeled also have anorthositic mineralogies and show similarities to both lunar FANs and anorthositic Mg-suite rocks.
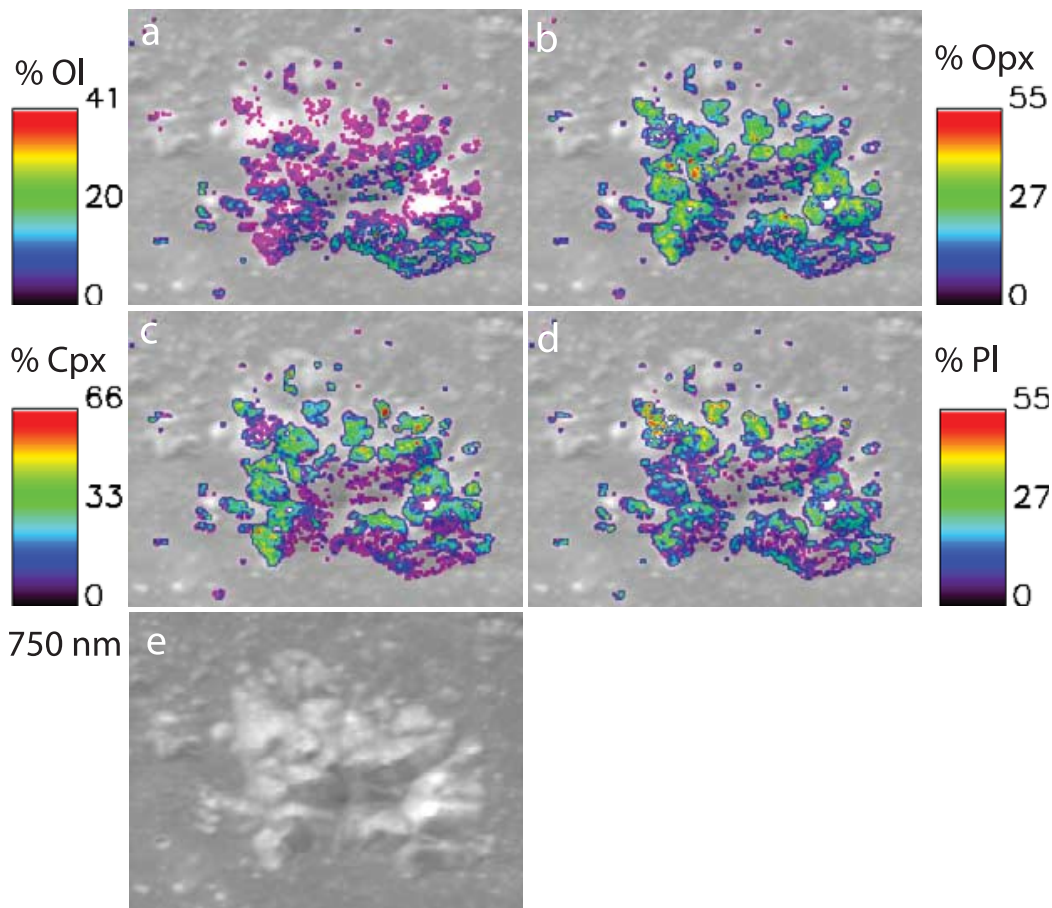

[26] The typical method to discern lunar petrologic suites is to compare mafic mineral $\mathrm{Mg}$ ' with one of the numerous "plagiophile-loving" elements or ratios (e.g., $\mathrm{Ca} / \mathrm{Ca}+\mathrm{Na}$, $\mathrm{Al}, \mathrm{Ti} / \mathrm{Sm}, \mathrm{Al} / \mathrm{Eu}$, etc.) [Warren and Kallemeyn, 1984]. The mafic Mg' versus plagioclase An method is the most often used because it can be accomplished easily and nondestructively with electron microprobe analysis of coexisting mafic and plagioclase minerals. However, in the context of spectral reflectance analysis these chemical distinctions for plagioclase cannot be achieved (at present). What we can determine with confidence is mafic $\mathrm{Mg}$ ' and

Figure 5. Model mineral maps of Finsen central peak inverted from Clementine VIS-NIR reflectance spectra and overlaid on a Clementine $750 \mathrm{~nm}$ reflectance image. Mineral abundance data for (a) olivine, (b) orthopyroxene, (c) clinopyroxene, and (d) plagioclase are displayed. Color scales are determined for the maximum abundance of each mineral. (e) A Clementine $750 \mathrm{~nm}$ band image of Finsen central peak is shown for context. 
Table 3. Model Mineralogy for Lunar Impact Crater Central Peaks

\begin{tabular}{|c|c|c|c|c|c|c|c|}
\hline Crater Name & Lithology & $\mathrm{Ol}(\mathrm{vol} \%)$ & Opx (vol \%) & Cpx (vol \%) & $\mathrm{Pl}(\mathrm{vol} \%)$ & Mafics/Pl & $\mathrm{Opx} / \mathrm{Cpx}$ \\
\hline Aitken & troctolite & 33.0 & 4.5 & 3.5 & 59.0 & 0.7 & 1.3 \\
\hline Alder & ol-noritic gabbro & 15.3 & 18.2 & 27.9 & 38.6 & 1.6 & 0.7 \\
\hline Antoniadi & ol-norite & 16.9 & 34.9 & 7.7 & 40.5 & 1.5 & 4.5 \\
\hline Aristillus & ol-gabbroic norite & 14.5 & 36.0 & 29.7 & 19.8 & 4.1 & 1.2 \\
\hline Aristoteles & ol-noritic gabbro & 13.3 & 22.5 & 28.9 & 35.2 & 1.8 & 0.8 \\
\hline Arzachel & anorth troctolite & 26.2 & 7.7 & 3.8 & 62.3 & 0.6 & 2.0 \\
\hline Atlas & anorth gabbro & 9.1 & 11.7 & 17.3 & 61.9 & 0.6 & 0.7 \\
\hline Bel'kovich & garbbroic anorthosite & 3.8 & 4.5 & 7.6 & 84.0 & 0.2 & 0.6 \\
\hline Berkner & anorth norite & 7.1 & 8.9 & 8.8 & 75.2 & 0.3 & 1.0 \\
\hline Bettinus & noritic anorthosite & 2.5 & 14.2 & 4.2 & 79.2 & 0.3 & 3.4 \\
\hline Bhabha & ol-noritic gabbro & 21.5 & 27.0 & 29.9 & 21.5 & 3.7 & 0.9 \\
\hline Birkeland & ol-noritic gabbro & 16.4 & 23.3 & 40.4 & 19.9 & 4.0 & 0.6 \\
\hline Borman & ol-norite & 37.5 & 10.0 & 0.0 & 52.5 & 0.9 & - \\
\hline Bose & ol-gabbroic norite & 14.6 & 26.9 & 26.4 & 32.1 & 2.1 & 1.0 \\
\hline Boyle & ol-gabbroic norite & 27.7 & 24.9 & 9.3 & 38.1 & 1.6 & 2.7 \\
\hline Bullialdus & gabbroic norite & 9.9 & 33.5 & 14.0 & 42.6 & 1.3 & 2.4 \\
\hline Burg & noritic gabbro & 7.6 & 15.1 & 41.2 & 36.2 & 1.8 & 0.4 \\
\hline Carpenter & noritic anorthosite & 3.3 & 9.8 & 5.0 & 81.9 & 0.2 & 2.0 \\
\hline Clavius & anorth gabbro & 7.1 & 7.3 & 11.0 & 74.5 & 0.3 & 0.7 \\
\hline Compton & anorth gabbro & 17.4 & 7.8 & 10.6 & 64.2 & 0.6 & 0.7 \\
\hline Copernicus & troctolite & 72.2 & 1.2 & 4.7 & 22.0 & 3.6 & 0.3 \\
\hline Crommelin & ol-noritic gabbro & 12.8 & 18.8 & 20.0 & 48.4 & 1.1 & 0.9 \\
\hline Crommelin $\mathrm{C}$ & ol-noritic gabbro & 21.7 & 17.3 & 11.6 & 49.4 & 1.0 & 1.5 \\
\hline Crookes & anorth gabbro & 13.1 & 3.7 & 21.8 & 61.4 & 0.6 & 0.2 \\
\hline Davisson & peridotite (pyroxenite) & 35.1 & 17.4 & 41.2 & 6.3 & 14.8 & 0.4 \\
\hline Dryden & ol-gabbroic norite & 6.9 & 28.9 & 26.6 & 37.5 & 1.7 & 1.1 \\
\hline Eijkman & ol-gabbroic norite & 10.8 & 28.9 & 11.9 & 48.5 & 1.1 & 2.4 \\
\hline Eijkman D & ol-noritic gabbro & 13.3 & 13.6 & 39.7 & 33.4 & 2.0 & 0.3 \\
\hline Finsen & gabbroic norite & 9.4 & 32.7 & 32.5 & 25.4 & 2.9 & 1.0 \\
\hline Fizeau & gabbroic norite & 6.2 & 32.5 & 22.7 & 38.6 & 1.6 & 1.4 \\
\hline Grissom M & ol-gabbroic norite & 24.3 & 17.9 & 12.1 & 45.7 & 1.2 & 1.5 \\
\hline Hopmann & ol-noritic gabbro & 21.2 & 18.6 & 20.5 & 39.7 & 1.5 & 0.9 \\
\hline Jackson & anorth gabbro & 10.5 & 6.4 & 18.4 & 64.7 & 0.5 & 0.3 \\
\hline Joliot & troc anorthosite & 11.1 & 1.5 & 4.9 & 82.5 & 0.2 & 0.3 \\
\hline Keeler & troc anorthosite & 13.4 & 0.2 & 0.6 & 85.9 & 0.2 & 0.3 \\
\hline King & ol-gabbro & 19.6 & 7.6 & 39.2 & 33.5 & 2.0 & 0.2 \\
\hline Langmuir & ol-noritic gabbro & 17.6 & 9.5 & 20.0 & 52.9 & 0.9 & 0.5 \\
\hline Lemaitre S & ol-norite & 31.0 & 20.6 & 5.7 & 42.7 & 1.3 & 3.6 \\
\hline Lowell & anorth troctolite & 19.9 & 9.6 & 8.6 & 62.0 & 0.6 & 1.1 \\
\hline Lyman & gabbroic norite & 6.4 & 41.0 & 10.3 & 42.2 & 1.4 & 4.0 \\
\hline Maksutov & ol-gabbroic norite & 11.7 & 41.4 & 31.5 & 15.4 & 5.5 & 1.3 \\
\hline Maunder & noritic gabbro & 9.4 & 15.2 & 50.3 & 25.1 & 3.0 & 0.3 \\
\hline $\mathrm{Ohm}$ & gabbro & 9.4 & 7.3 & 44.8 & 38.5 & 1.6 & 0.2 \\
\hline Orlov & ol-noritic gabbro & 13.1 & 15.0 & 31.2 & 40.6 & 1.5 & 0.5 \\
\hline Pythagoras & anorth gabbro & 8.9 & 4.6 & 12.1 & 74.4 & 0.3 & 0.4 \\
\hline Scaliger & ol-noritic gabbro & 28.6 & 8.1 & 23.2 & 40.0 & 1.5 & 0.4 \\
\hline Stevinus & ol-gabbroic norite & 19.2 & 13.7 & 9.7 & 57.4 & 0.7 & 1.4 \\
\hline Stoney & ol-noritic gabbro & 38.8 & 20.6 & 28.1 & 12.4 & 7.0 & 0.7 \\
\hline Theophilus & anorth troctolite & 25.3 & 4.4 & 10.1 & 60.1 & 0.7 & 0.4 \\
\hline Tsiolkovsky & ol-gabbro & 19.1 & 7.2 & 25.5 & 48.1 & 1.1 & 0.3 \\
\hline Tycho & ol-noritic gabbro & 15.6 & 9.0 & 23.4 & 51.9 & 0.9 & 0.4 \\
\hline Vavilov & anorth gabbro & 8.5 & 5.1 & 16.1 & 70.4 & 0.4 & 0.3 \\
\hline Von Karman & ol-noritic gabbro & 22.7 & 12.3 & 19.1 & 45.9 & 1.2 & 0.6 \\
\hline White & ol-gabbroic norite & 46.3 & 25.6 & 17.5 & 10.6 & 8.5 & 1.5 \\
\hline Zucchius & noritic gabbro & 9.6 & 13.0 & 17.9 & 59.4 & 0.7 & 0.7 \\
\hline
\end{tabular}

plagioclase abundance. Cahill and Lucey [2007] reported a compilation of modal mineralogy and $\mathrm{Mg}$ ' for $\sim 100$ lunar FAN and Mg-suite rocks. In Figure 7a, examination of these data show that taking the mean $\mathrm{Mg}$ ' of the mafic minerals weighted by their relative proportions and the mean plagioclase abundance effectively separate the lunar FAN and Mg' petrologic suites. To a large degree this method also separates the rock types within the Mg-suite. With this knowledge we have a method to make direct comparisons between remotely determined impact crater central peak composition and the lunar sample collection. Here, model results show that the selection of lunar central peaks analyzed are dominantly similar to $\mathrm{Mg}$-suite rocks (Figure 7b). These Mg-suite-like peaks are plagioclase-poor $(<60 \mathrm{vol} \%)$ and vary from ferroan to magnesian varieties (Mg' 55-94), or may be plagioclase-rich (>60 vol \%) with an $\mathrm{Mg}$ of $78-85$. A few central peaks also show some similarity to FAN rocks with greater than 70 vol \% plagioclase and Mg's of $\sim 70-75$. Although the central peak modeled rock types do not necessarily perfectly overlap the fields defined by the samples, the basic distinction between ferroan and magnesian rocks is present, as is the general correlation of plagioclase with $\mathrm{Mg}^{\text {' }}$ in the mafic peaks. We should also note that this diagram cannot 


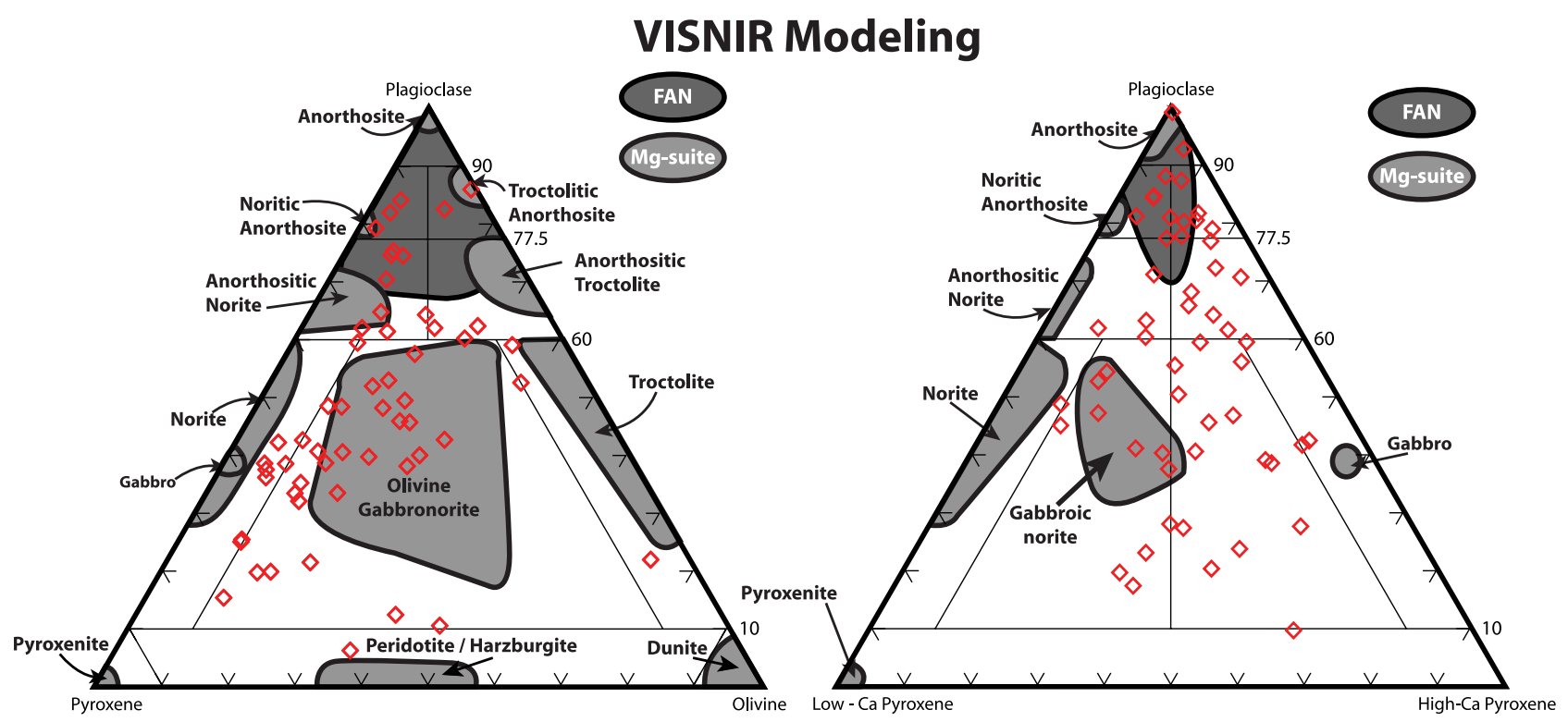

Figure 6. Mean mineral assemblages for each impact crater central peak analyzed compared to known assemblages of the lunar sample suites (gray, ferroan anorthosite (FAN); dark gray, Mg-suite) on plutonic rock classification diagrams [Stöffler et al., 1980].

distinguish alkali from ferroan anorthosites. Here we will assume ferroan, plagioclase-rich compositions are FAN.

\subsection{Composition Relative to Crustal Thickness}

[27] Although the correlation is weak, it is apparent that plagioclase gradually increases as the crust thickens with peaks often having anorthositic ( $>60$ vol \% plagioclase) mineral assemblages above crustal thicknesses of $60 \mathrm{~km}$ (Figure 8). For crust thinner than $60 \mathrm{~km}$, peaks tend to be mafic ( $>\sim 50$ vol \% mafics). Olivine and orthopyroxene abundances range from near 0 to $\sim 45$ vol $\%$ and do vary as crustal thickness changes. Again, this variation is not highly correlated but is apparent. In thicker crust (i.e., $>50 \mathrm{~km}$ ), both olivine and orthopyroxene abundances are low $(<15$ to $20 \mathrm{vol} \%$ ) in all peaks analyzed. However, as the crust thins the maximum observed abundance of these two minerals for many peaks increases until they each reach their highest overall abundances $(\sim 45 \mathrm{vol} \%)$ in crust less than $\sim 30 \mathrm{~km}$ thick. But, although olivine- and orthopyroxene-rich lithologies are observed exclusively in thin crust, other varieties of lithologies with less abundant proportions of these two minerals are observed in thin crust as well. This increase in orthopyroxene as the crust thins is also reflected in the overall pyroxene abundance, as the orthopyroxene/clinopyroxene ratio increases from less than 0.5 in thick crust to greater than 4 in thin crust. In crust greater than $60 \mathrm{~km}$ thick average clinopyroxene abundance is less than 25 volume percent; but in crust less than $60 \mathrm{~km}$ thick clinopyroxene maximum abundance increases to $\sim 45 \mathrm{vol} \%$ but has an overall range of $0-45 \mathrm{vol} \%$. Model Mg' shows a relatively magnesian Mg' range of 70-85 in both thick and thin crust; however, as the crust thins to less than $35 \mathrm{~km}$, more ferroan ( $\mathrm{Mg}^{\prime} 58-70$ ) peaks are also present. Although $\mathrm{FeO}$ increases in thin crust relative to thick, several peaks show more ferroan compositions as FeO increases from thick $(\sim 7 \mathrm{wt} \%)$ to thin $(>18 \mathrm{wt} \%)$ crust.

\subsection{Composition Relative to Peak Origin}

[28] Here we relate the composition of the central peaks analyzed to their origin in the crustal column. An estimate of exhumation depth scaled to the thickness of the crust, $R$, (e.g., Ratio $=$ thickness - depth/thickness) shows that most peaks analyzed originated from nearly all depths possible in the crustal column, but no compositional trends are discerned (Figure 9). This may suggest that there are no compositional trends within the crust and that composition is only a function of crustal thickness, but this assumes crustal structure is independent of thickness, and has been preserved since it was established. When we use the crustmantle boundary as our reference point by determining $P$ (e.g., Proximity = thickness - depth) compositional trends, although weakly correlated, are shown to be present (Figure 10). The crust-mantle boundary acts as a good reference point because it was established at the same time as crustal formation and is not affected by material stripped away by impact bombardment. Even in the case of SPA and its plausible isostatic rebound after basin formation, stratigraphic compositional relationships should be more intact near the crust-mantle boundary unless impact melting occurred deeply enough to destroy these relationships by creating an impact melt sheet that extends deep below SPA [Morrison, 1998].

[29] Model mineralogy between 40 and $80 \mathrm{~km}$ from the crust-mantle interface show low abundances of olivine and orthopyroxene $(<15$ to 20 vol \%); only clinopyroxene maintains greater than $20 \mathrm{vol} \%$ within this proximity to the mantle boundary. Model peak plagioclase abundance is on average largely anorthositic ( $>60$ vol \% plagioclase) $50 \mathrm{~km}$ above the interface. Mineralogy within $40 \mathrm{~km}$ of the crust-mantle boundary and below is diverse, with both highly mafic and plagioclase-rich lithologies present. Mafic lithologies ( $>40$ vol \% mafics) are largely confined to the crust within $40 \mathrm{~km}$ of the crust-mantle boundary, whereas 

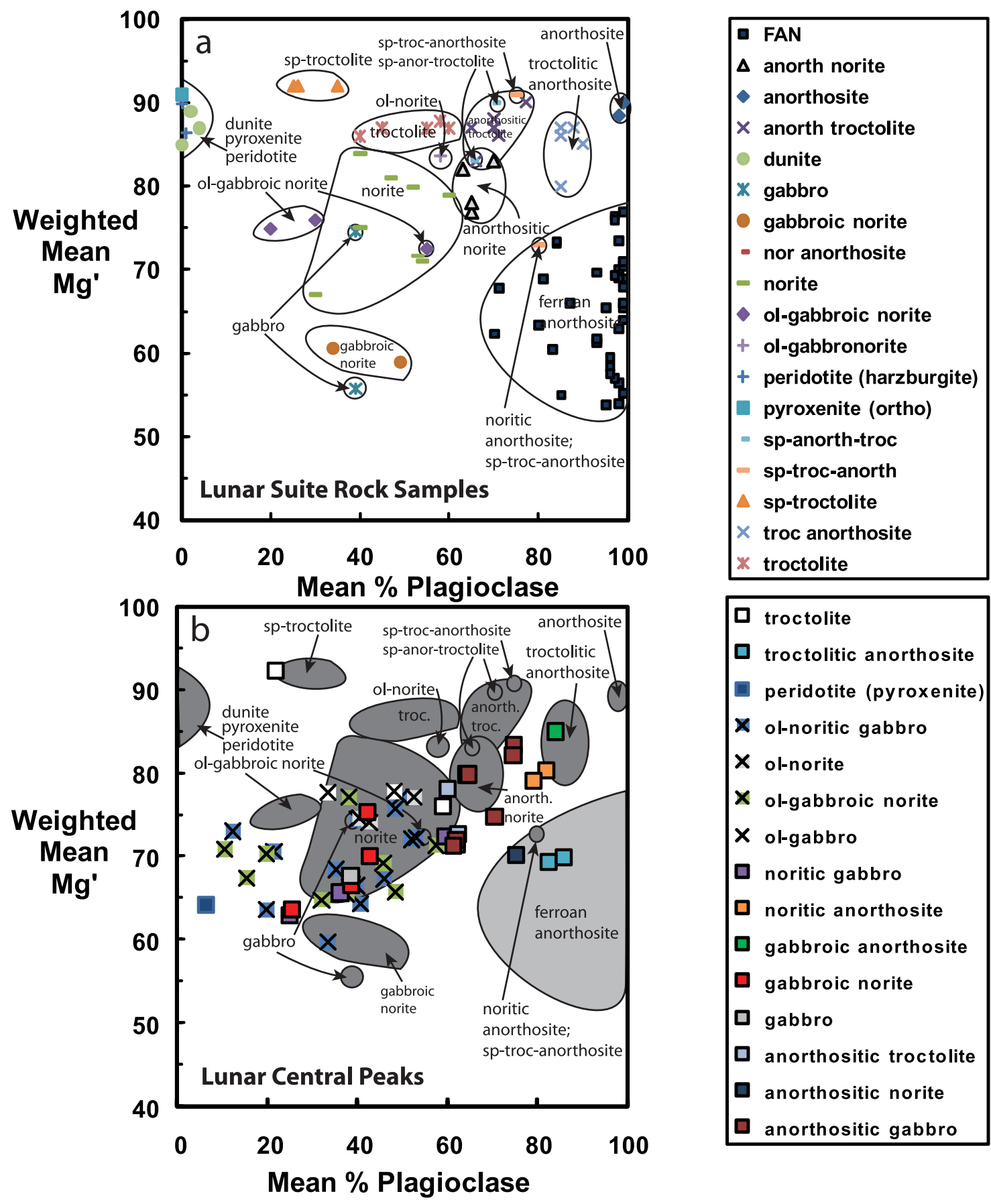

\begin{tabular}{|l|}
\hline$\square$ troctolite \\
$\square$ troctolitic anorthosite \\
$\times$ peridotite (pyroxenite) \\
$\times$ ol-noritic gabbro \\
$\times$ ol-norite \\
$\times$ ol-gabbroic norite \\
$\times$ ol-gabbro \\
$\square$ noritic gabbro \\
$\square$ noritic anorthosite \\
$\square$ gabbroic anorthosite \\
$\square$ gabbroic norite \\
$\square$ gabbro \\
$\square$ anorthositic troctolite \\
$\square$ anorthositic norite \\
$\square$ anorthositic gabbro \\
\hline
\end{tabular}

Figure 7. Lunar FAN and Mg-suite sample comparison using mafic weighted mean Mg' versus plagioclase abundance. (a) Sample data points are displayed and Mg-suite samples are denoted by lithology. (b) Peak average assemblages are displayed.

plagioclase-rich ( $>60 \mathrm{vol} \%$ ) lithologies are seen throughout the crustal column.

[30] Peak chemistry $40-80 \mathrm{~km}$ away from the crustmantle boundary is magnesian $(\mathrm{Mg}, 70-80)$ despite low $\mathrm{FeO}(<7$ wt \%) and anorthositic (>60 vol \%) lithologies. More compositional diversity is observed from peaks that originate closer to (i.e., within 0 to $40 \mathrm{~km}$ ) the crust-mantle boundary; these peaks range in $\mathrm{Mg}$ ' from ferroan $(\sim 60)$ to more magnesian $(\sim 93)$ lithologies.

\subsection{Composition of Peaks Laterally}

[31] The compositional diversity of peaks in the lateral perspective is largely consistent with lunar terrane [Jolliff et al., 2000; Wieczorek and Phillips, 2000]. In Figure 11, peaks with anorthositic ( $\geq 60$ vol \%) modeled mineralogy are nearly exclusively confined to the FHT terrane. Crater peaks in this terrane with some of the highest-modeled plagioclase abundances ( $>80$ vol \%), including Bel'kovich, Carpenter, Joliot, and Keeler are also shown to originate in 

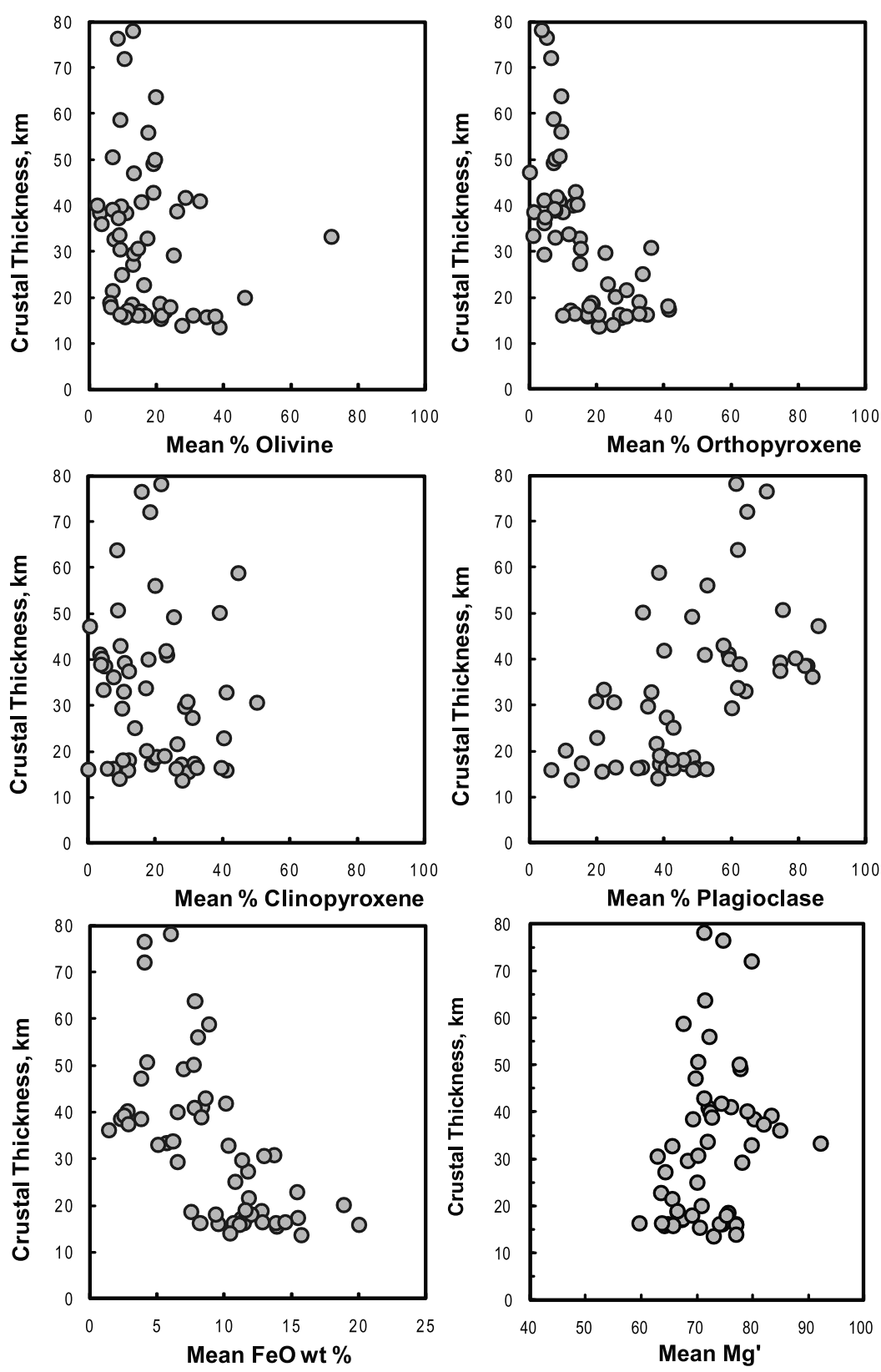

Figure 8. Mean lunar impact crater central peak mineralogy and chemistry versus crustal thickness $\left(T_{1}\right)$.

the lower crust or mantle. Only Maunder on the northern end of Orientale and $\mathrm{Ohm}$ crater have less than $60 \mathrm{vol} \%$ plagioclase. The outer FHT shows a little more diversity with a few peaks averaging less than $60 \mathrm{vol} \%$ plagioclase, but the majority of peaks still have anorthositic average mineralogies. Model peak mineralogy within the PKT and SPA is all mafic ( $<60$ vol $\%$ plagioclase); SPA peaks also show less plagioclase $(<50$ vol \%) abundances than the PKT and vary from basin edges $(20-50 \mathrm{vol} \%)$ to the basin center ( $<20$ vol \% plagioclase).

[32] Mafic minerals also associate with terrane, with olivine primarily concentrated within SPA (6-46 vol \%, outer to inner basin, respectively). Only Copernicus peak within the PKT is modeled to have greater olivine abundance $(72 \mathrm{vol} \%)$ than peaks within SPA. Orthopyroxene is also concentrated within SPA with range of 12 to 41 vol \%, but is also prevalent on the PKT crater peaks Aristoteles (22 vol \%), Bullialdus (33 vol \%), and Aristillus (36 vol \%). Clinopyroxene is the only mineral with abundances that appear to be independent of terrane. This result may be real, or may indicate a systematic error in the modeling results.

\section{Discussion}

[33] Previous studies have reported compelling evidence to suspect that the crust changes composition with depth. These observations include (1) the identification of large impact basin ejecta that are more mafic than the surrounding highlands [e.g., Reid et al., 1977; Ryder and Wood, 1977; Spudis and Davis, 1986], (2) central peaks of some complex 


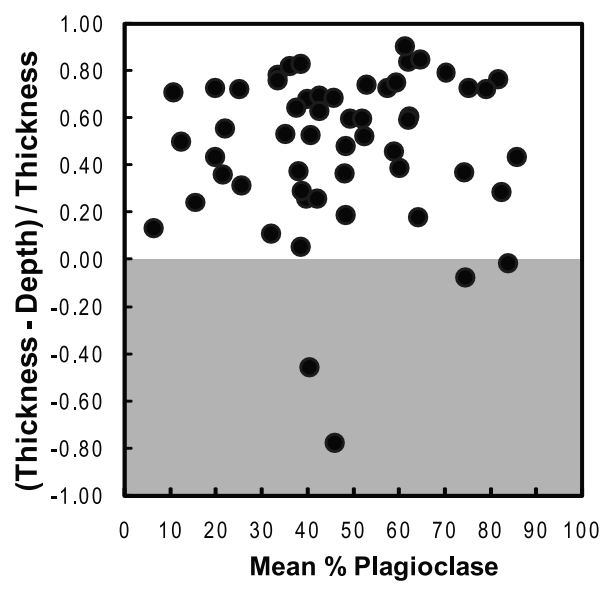

Figure 9. Plagioclase abundances versus the origin of impact crater central peak materials. The origin of the central peak materials is represented by ratios calculated on the basis of the proximity to mantle relative to the local crustal thickness. Peaks with ratios greater than zero originated in the crust; peaks with ratios less than zero (in gray) originated in the mantle (e.g., $\left.\left(T_{1}-D_{1}\right) / T_{1}\right)$.

craters that are inferred to contain mafic lithologies [e.g., Tompkins and Pieters, 1999], and (3) the inferred noritic composition of the SPA basin floor which is suggested to represent lower crustal materials [e.g., Lucey et al., 1995; Pieters et al., 1997, 2001; Wieczorek and Zuber, 2001].

[34] All peaks examined here have strong mineral and major element abundances consistent with rocks of the lunar sample collection. The majority of the peaks examined consist of material with mafic and magnesian composition similar to Mg-suite rocks that are spread among all of the lunar terranes. We suggest that our direct comparison of lunar samples and peaks provide evidence that the majority of these peaks consist of Mg-suite rocks. The few peaks where FAN compositions are identified are confined within the FHT (craters Berkner, Joliot, and Keeler). This prevalence of mafic and magnesian peaks and the paucity of peaks with anorthosite and FAN composition may be explained by our method of crater peak sampling. The peaks examined are all estimated to originate at least $10 \mathrm{~km}$ or more below the lunar surface. The observed compositional bias might be expected especially if the crust becomes more mafic with depth. Additional anorthositic peaks may be apparent if peaks originating in the top $10 \mathrm{~km}$ of the lunar crust are examined in future work.

[35] Despite the commonalities between these peak analyses and Mg-suite rocks, it is a possible interpretation that some of these peaks may consist of mafic ferroan rocks (e.g., mafic FANs) [Wieczorek and Zuber, 2001]. Although this is a reasonable hypothesis, little evidence is available for this in the sample collection and several samples that are suggested to be representative mafic ferroan rocks are far less mafic than the peaks reported here and still plot within the FAN field in Figure 7 [Jolliff and Haskin, 1995; Wieczorek et al., 2006]. However, the presence of mafic ferroan rocks on the Moon merits further investigation in the future.
[36] The mineral and major element results presented here suggest these peaks are consistent with $\mathrm{Mg}$-suite rocks, but many of these peaks lack thorium anomalies that would suggest KREEP signatures. Previous studies of Mg-suite rocks show significant enrichments (at least 1-2 orders of magnitude) in KREEP and other incompatible elements relative to FAN rocks [e.g., Papike et al., 1994; Papike et al., 1996; Shervais and McGee, 1998a, 1998b; Wieczorek et al., 2006]. The current hypothesis for lunar Mg-suite formation suggests high concentrations of incompatible elements are at least assimilates [Warren, 1986]; whether high incompatibles are necessary for Mg-suite formation remains unknown. However, since the rocks of this suite were collected from every Apollo landing site within the PKT and this region has a pronounced thorium anomaly, it has been suggested that $\mathrm{Mg}$-suite rocks may be spatially confined to this region and incompatible elements are a genetic signature of this suite [Jolliff et al., 2000; Korotev, 2000; Korotev and Gillis, 2001; Wieczorek and Phillips, 2000].

[37] However, it should be pointed out that although "magnesian" and "Mg-suite" might be equivalent, magnesian rocks that do not contain KREEP might also exist, and may or may not be genetically related to the Mg-suite rocks. An increasing body of evidence suggests that, at the very least, magnesian compositions on the Moon are not limited to the PKT. Recent studies of KREEP-poor, feldspathic and magnesian lunar meteorites inferred to originate in the farside FHT suggest the presence of a magnesian component that influenced their formation [Korotev et al., 2003; Warren et al., 2005]; however, the characterization of this magnesian component is under question. Korotev [2005] suggests that the magnesian component of these meteorites is not from a Mg-suite source. Since these meteorites do not contain mafic magnesian and KREEP bearing lithologies typical of Mg-suite rocks, Korotev [2005] suggests these feldspathic meteorites are derived from magnesian, rather than ferroan, anorthosites. Warren [2005] and Warren et al. [2005] support an attempt to extend the presence of the Mg-suite globally by suggesting that the magnesian component in these meteorites is derived from a KREEP-poor or free variety of $\mathrm{Mg}$-suite (a characteristic that is not observed in the Apollo and Luna samples). The difficulty with either argument is the genesis of magnesian anorthositic rocks. Both Warren [2005] and Hess [1994] (the former addressing magnesian feldspathic meteorites and the latter addressing magnesian troctolites), point out that source magmas for magnesian feldspathic material would have to be extremely magnesian themselves, with $\mathrm{Mg}$ ' approaching that of the terrestrial mantle $\left(\mathrm{Mg}^{\prime} \sim 93\right)$.

[38] The central peaks analyzed here not only suggest a magnesian component in both KREEP-rich and KREEP-poor areas but may have sampled the source component suggested to be influencing the chemistry of lunar meteorites. Stoichiometrically estimating oxide abundance from mineralogy, these peaks have a similar $\mathrm{Al}_{2} \mathrm{O}_{3}$ range $(2-31 \mathrm{wt} \%)$ to the meteorite collection, but are also more magnesian. Greater compositional similarities are actually found between peaks and Mg-suite rocks of the lunar sample collection; however, a large sample of peaks are not located in areas of significant or even mild KREEP influence. In this context, positive identification of mafic 

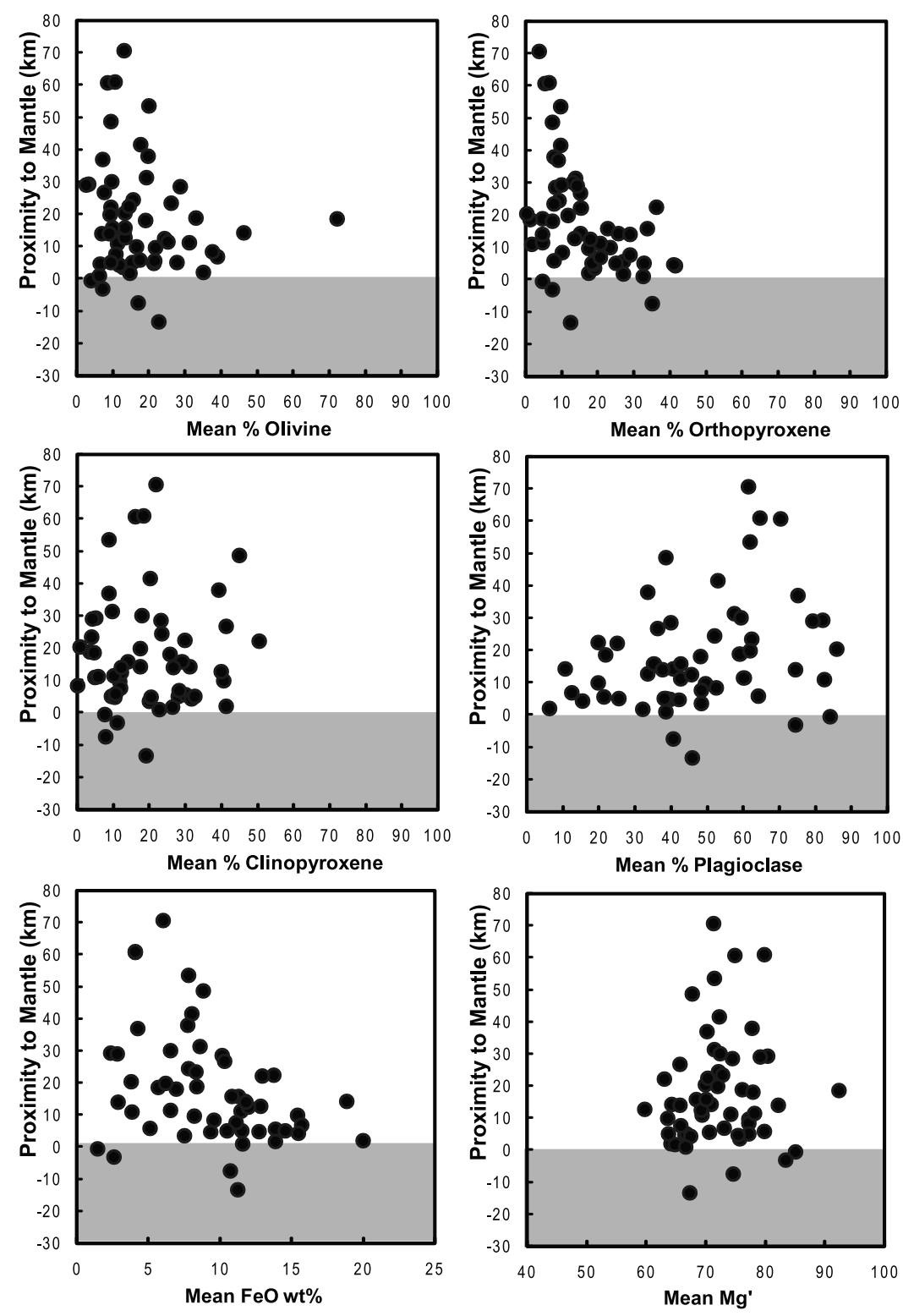

Figure 10. Mean lunar impact crater central peak mineralogy and chemistry versus peak origin relative to the crust mantle boundary (e.g., $T_{1}-D_{1}$ ). Proximity to mantle less than zero denotes materials plausibly derived from the lunar mantle (in gray).

and magnesian rocks here supports the hypothesis that high incompatible element abundances may not be a necessary genetic characteristic of $\mathrm{Mg}$-suite rocks and this suite may not be confined to the PKT. Whether incompatible elements help or speed Mg-suite rock formation is still a subject for debate, but the probable identification of $\mathrm{Mg}$-suite rocks within the FHT and SPA suggests high incompatible element abundances are not absolutely necessary for their production.

[39] Central peak compositions also roughly follow terrane boundaries. Peaks modeled with magnesian and ferroan anorthositic compositions are primarily confined to the FHT; while peaks with mafic model mineralogies are generally confined to the PKT and SPA with a few exceptions. This translates vertically within each terrane as a function of crustal thickness. As the crust thickens it becomes more anorthositic and magnesian, and as it thins it becomes more mafic and ferroan. The thinnest lunar crust
$(<30 \mathrm{~km})$, central SPA, shows the most mafic mineralogy ( $>50$ vol $\%$ outer SPA, $>80$ vol $\%$ inner SPA); while thicker crust ( $>30 \mathrm{~km}$; not necessarily the thickest), in the FHT, is more plagioclase-rich ( $>60$ vol \% plagioclase). This compositional relationship is also found relative to the crust-mantle boundary. Mafic lithologies, both magnesian and more ferroan, are confined to within $50 \mathrm{~km}$ of the crust mantle boundary in SPA and the PKT. Anorthositic lithologies are largely confined within the FHT, however, they exist at all levels of the crustal column and with a significant magnesian sampling.

[40] These results suggest the FHT, SPA, and the PKT may not only be distinct from each other on the surface but subsurface as well. Model compositional results for SPA and PKT central peaks are consistent with a crust gradually increasing in mafic mineralogy with depth. This is consistent with previous interpretations of PKT impact melts and 


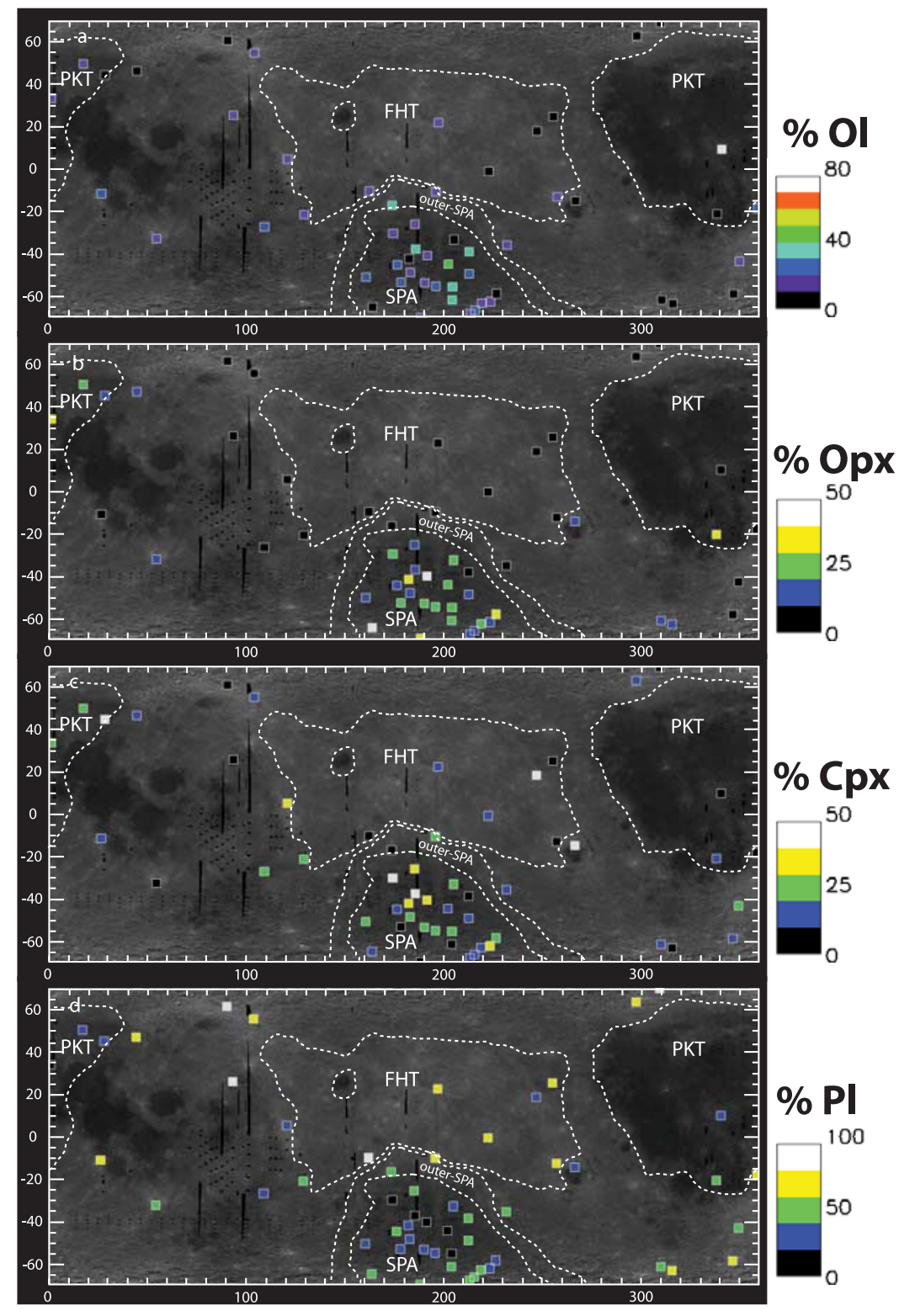

Figure 11. The location of crater peaks examined and their mean (a) olivine, (b) orthopyroxene, (c) clinopyroxene, and (d) plagioclase abundances plotted on Clementine $750 \mathrm{~nm}$ simple cylindrical images of the lunar surface. Dashed lines denote approximate lunar terrane boundaries interpreted from thorium maps [Jolliff et al., 2000; Lawrence et al., 2002].

basins noted early in this discussion. Not consistent with this hypothesis are peaks that show mafic mineralogies and more ferroan chemistries at significant depth in the crust. However, this is consistent with a scenario suggested by Warren et al. [2005] for the petrogenesis of lunar meteorites. In this scenario mafic and magnesian minerals crystallize first and begin to settle, but during the process of settling some of these mafic and magnesian crystals are entrained with subsequently crystallizing and more buoyant plagioclase minerals. These assemblages are transported upward in the magma ocean to become part of the crust in a higher stratigraphic location. Crystallization proceeds until less buoyant ferroan and more mafic lithologies crystallize and settle low in the crustal column with some of the initial early crystallizing and more magnesian mafic minerals. This scenario may be applicable for PKT and SPA crustal formation, but may not be sufficient for the FHT.

[41] Peaks within the FHT suggest that at least portions of this terrane (near the craters Bel'kovich, Carpenter, Joliot, Keeler, and others) can either (1) consist entirely of anorthositic rocks throughout the crustal column or (2) have a plagioclase-rich lower crustal layer with stalled plutons within $40 \mathrm{~km}$ of the crust-mantle boundary. The identification of anorthosite transported to the surface via impact basin inner rings and peaks of Orientale, Grimaldi, Humorum, Nectaris, and Apollo corroborate this interpretation [Hawke et al., 2003; Spudis et al., 1984]. However, the result here suggests both scenarios must have ferroan and magnesian anorthositic rocks at significant depth. This is inconsistent with previous hypotheses that the FHT has a 
generally increasing mafic composition with depth; but it is consistent with separate magnesian and ferroan magmas somewhat simultaneously constructing an anorthositic FHT, at least in the areas sampled. This is also consistent with FAN and Mg-suite radiometric ages which suggest that these suites crystallized simultaneously through a significant portion of lunar geologic history [Borg et al., 1999; Wieczorek et al., 2006], although caution is suggested for ages of plagioclase-rich samples owing to impact metamorphism modification [Norman et al., 2003].

\section{Conclusions}

[42] Here we provide several new insights into the relationship between lunar crustal composition and structure in both vertical and lateral perspectives.

[43] 1. We show that lunar composition varies with crustal thickness. As the crust thickens it becomes more plagioclase-rich, and as the crust thins it becomes more mafic.

[44] 2. Our method of using the crust-mantle boundary as a reference point has allowed us to pinpoint crater peaks that have sampled the lower crust and plausibly the mantle. Approximately half the peaks analyzed here plausibly represent mantle material.

[45] 3. No systematic compositional variability with respect to the depth of origin normalized to local crustal thickness is found; however, significant compositional relationships are shown relative to the crust-mantle boundary. This suggests that the majority of compositional variations in the crust were in place before major surface modifications took place.

[46] 4. Mafic lithologies ( $\geq 40$ vol \% mafics) are confined to thin crust that is within $50 \mathrm{~km}$ of the lunar crust-mantle boundary and within the SPA and PKT terranes with a few exceptions; the most mafic lithologies ( $>80$ vol \% mafics) are confined within $30 \mathrm{~km}$ of the crust-mantle boundary within SPA. These results are consistent with a gradually increasing mafic/plagioclase ratio traveling down into the crust.

[47] 5. Anorthositic ( $\geq 60$ vol \% plagioclase) rocks are found throughout the crustal column, but are dominantly confined within the FHT and outer FHT; however, some peaks with greater than 70 vol \% plagioclase do exist in crust that is $30-50 \mathrm{~km}$ thick and relatively near the crustmantle boundary. These results are inconsistent with a generally increasing mafic composition with depth, and instead support a dominantly anorthositic crustal column with a distinct layer or intrusions of more plagioclase-rich magnesian and ferroan anorthositic rocks at significant depth in the crust.

[48] 6. The majority of peaks analyzed have compositions similar to $\mathrm{Mg}$-suite rocks of the lunar sample collection and they are found to be independent of lunar terrane. This suggests that $\mathrm{Mg}$-suite rocks may not be confined to the PKT and may not be dependent on incompatible element concentrations for formation. These results also suggest Mg-suite rocks may be a global phenomenon and may have wide ranging incompatible element and mineral abundances; but the main factors that determine $\mathrm{Mg}$-suite rock formation are major element chemistry and geophysical dynamics. Incompatible element enrichment may be an added attribute of $\mathrm{Mg}$-suite rocks within PKT and perhaps to a lesser extent SPA.

\section{Future Work}

[49] Future work will entail a continuation of analysis of lunar impact crater central peaks especially within the FHT and PKT. Integration of new data from Chang'e, Chandrayaan-1, Kaguya, Lunar Reconnaissance Orbiter, and Gravity Recovery And Interior Laboratory (GRAIL) will be essential. These data will be beneficial for more rigorously calibrated reflectance data relative to surface slopes and determining subsurface crustal structure to correlate with compositional interpretations. Further research and development of quantitative analysis models, mineral optical constants, and supporting validation data sets are essential.

[50] The results shown here appear to confirm that SPA is a window into the lunar lower crust. However, it is possible that the floor of SPA basin may represent an impact melt sheet that may have partially differentiated and represent something very different from a cross section of the original crust [Morrison, 1998]. Further analysis of impact crater walls in addition to central peaks will help resolve this issue. Additional cataloging and assessments of lunar samples for mafic ferroan rocks is also necessary.

[51] Acknowledgments. The authors give their gratitude to B. Denevi and K.R. Stockstill-Cahill for constructive discussions on spectral modeling as well as W. Koeppen, E. Pilger, and R. Snider for helpful discussions and advice on IDL programming and Condor parallel processing techniques. Use of the Hawaii Institute of Geophysics and Planetology (HIGP) computer cluster and parallel processing facilities was instrumental for this study. This work was funded by NASA grant NNX07AU96G (e.g., Mineral Mapping of the Moon) to P.G. Lucey. This is SOEST, HIGP, and IPGP contribution 7746,1786 , and 2501 , respectively.

\section{References}

Borg, L. E., M. Norman, L. Nyquist, D. Bogard, G. Snyder, L. A. Taylor, and M. Lindstrom (1999), Isotopic studies of ferroan anorthosite 62236: A young lunar crustal rock from a light-rare-Earth-element-depleted source, Geochim. Cosmochim. Acta, 63, 2679-2691, doi:10.1016/S00167037(99)00130-1.

Cahill, J. T., and P. G. Lucey (2007), Radiative transfer modeling of lunar highlands spectral classes and relationship to lunar samples, J. Geophys. Res., 112, E10007, doi:10.1029/2006JE002868.

Cintala, M. J., and R. A. F. Grieve (1998), Scaling impact melting and crater dimensions: Implications for the lunar cratering record, Meteorit. Planet. Sci., 33, 889-912.

Clark, B. E., et al. (2001), Space weathering on Eros: Constraints from albedo and spectral measurements of Psyche crater, Meteorit. Planet. Sci., 36, 1617-1637.

Croft, S. K. (1980), Cratering flow fields: Implications for the excavation and transient expansion stages of crater formation, Proc. Lunar Planet. Sci. Conf., 11th, 2347-2378.

Dence, M. R. (1968), Shock zoning at Canadian craters: Petrography and structural implications, in Shock Metamorphism of Natural Materials, edited by B. M. French and N. M. Short, pp. 169-184, MonoBooks, Baltimore, Md.

Denevi, B. W., P. G. Lucey, and S. B. Sherman (2008), Radiative transfer modeling of near-infrared spectra of lunar mare soils: Theory and measurement, J. Geophys. Res., 113, E02003, doi:10.1029/2007JE002929.

Hapke, B. (1981), Bidirectional reflectance spectroscopy: 1. Theory, J. Geophys. Res., 86, 3039-3054, doi:10.1029/JB086iB04p03039.

Hapke, B. (1993), Theory of Reflectance and Emittance Spectroscopy, Cambridge Univ. Press, New York.

Hapke, B. (2001), Space weathering from Mercury to the asteroid belt, J. Geophys. Res., 106, 10,039-10,073, doi:10.1029/2000JE001338.

Hawke, B. R., P. G. Lucey, G. J. Taylor, J. F. Bell, C. A. Peterson, D. T. Blewett, K. Horton, and G. A. Smith (1991), Remote sensing studies of the orientale region of the moon: A pre-Galileo view, Geophys. Res. Lett., 18, 2141-2144, doi:10.1029/91GL02667. 
Hawke, B. R., C. A. Peterson, P. G. Lucey, G. J. Taylor, D. T. Blewett, B. A. Campbell, C. R. Coombs, and P. D. Spudis (1993), Remote sensing studies of the terrain northwest of Humorum Basin, Geophys. Res. Lett., 20, 419-422, doi:10.1029/92GL02921.

Hawke, B. R., C. A. Peterson, D. T. Blewett, D. B. J. Bussey, P. G. Lucey, G. J. Taylor, and P. D. Spudis (2003), Distribution and modes of occurrence of lunar anorthosite, J. Geophys. Res., 108(E6), 5050 doi:10.1029/2002JE001890.

Hess, P. C. (1994), Petrogenesis of lunar Troctolites, J. Geophys. Res., 99 19,083 - 19,093, doi:10.1029/94JE01868

James, O. B. (1980), Rocks of the early lunar crust, Proc. Lunar and Planet. Sci. Conf., 11th, 365-393.

Jolliff, B. L., and L. A. Haskin (1995), Cogenetic rock fragments from a lunar soil: Evidence of a ferroan noritic-anorthosite pluton on the Moon, Geochim. Cosmochim. Acta, 59, 2345-2374, doi:10.1016/00167037(95)00110-L.

Jolliff, B. L., J. J. Gillis, L. A. Haskin, R. L. Korotev, and M. A. Wieczorek (2000), Major lunar crustal terranes: Surface expressions and crustmantle origins, J. Geophys. Res., 105, 4197-4216, doi:10.1029/ 1999JE001103.

Khan, A., and K. Mosegaard (2002), An enquiry into the lunar interior: A nonlinear inversion of the Apollo lunar seismic data, J. Geophys. Res., 107(E6), 5036, doi:10.1029/2001JE001658

Khan, A., K. Mosegaard, and K. L. Rasmussen (2000), A new seismic velocity model for the Moon from a monte carlo inversion of the Apollo lunar seismic data, Geophys. Res. Lett., 27, 1591-1594, doi:10.1029/ 1999GL008452.

Korotev, R. L. (2000), The great lunar hot spot and the composition and origin of the Apollo mafic ("LKFM") impact-melt breccias, J. Geophys. Res., 105, 4317-4345, doi:10.1029/1999JE001063.

Korotev, R. L. (2005), Lunar geochemistry as told by lunar meteorites, Chem Erde Geochem., 65, 297-346, doi:10.1016/j.chemer.2005.07.001.

Korotev, R. L., and J. J. Gillis (2001), A new look at the Apollo 11 regolith and KREEP, J. Geophys. Res., 106, 12,339-12,353, doi:10.1029/ 2000JE001336.

Korotev, R. L., B. L. Jolliff, R. A. Zeigler, J. J. Gillis, and L. A. Haskin (2003), Feldspathic lunar meteorites and their implications for compositional remote sensing of the lunar surface and the composition of the lunar crust, Geochim. Cosmochim. Acta, 67, 4895-4923, doi:10.1016/ j.gca.2003.08.001

Lawrence, S. J., and P. G. Lucey (2007), Radiative transfer mixing models of meteoritic assemblages, J. Geophys. Res., 112, E07005, doi:10.1029/ 2006JE002765.

Lawrence, D. J., W. C. Feldman, R. C. Elphic, R. C. Little, T. H. Prettyman, S. Maurice, P. G. Lucey, and A. B. Binder (2002), Iron abundances on the lunar surface as measured by the Lunar Prospector gamma-ray and neutron spectrometers, J. Geophys. Res., 107(E12), 5130, doi:10.1029/ 2001JE001530.

Lognonne, P., J. Gagnepain-Beyneix, and H. Chenet (2003), A new seismic model of the Moon: Implication for structure, thermal evolution and formation of the Moon, Earth Planet. Sci. Lett., 211, 27-44 doi:10.1016/S0012-821X(03)00172-9.

Lucey, P. G. (1998), Model near-infrared optical constants of olivine and pyroxene as a function of iron content, J. Geophys. Res., 103, 17031713, doi:10.1029/97JE03145.

Lucey, P. G. (2004), Mineral maps of the Moon, Geophys. Res. Lett., 31, L08701, doi:10.1029/2003GL019406.

Lucey, P. G., and S. K. Noble (2008), Experimental test of a radiative transfer model of the optical effects of space weathering, Icarus, 197, 348-353, doi:10.1016/j.icarus.2008.05.008.

Lucey, P. G., G. J. Taylor, and E. Malaret (1995), Abundance and distribution of iron on the Moon, Science, 268, 1150-1153, doi:10.1126/ science.268.5214.1150

Lucey, P. G., D. T. Blewett, G. J. Taylor, and B. R. Hawke (2000), Imaging of lunar surface maturity, J. Geophys. Res., 105, 20,377-20,386, doi:10.1029/1999JE001110.

Melosh, H. J. (1989), Impact Cratering: A Geologic Process, 245 pp., Oxford Univ. Press, New York.

Morrison, D. A. (1998), Did a thick South Pole-Aitken basin melt sheet differentiate to form cumulates?, Lunar Planet. Sci. [CD-ROM], XXIX, Abstract 1657.

Norman, M. D., L. E. Borg, L. E. Nyquist, and D. D. Bogard (2003), Chronology, geochemistry, and petrology of a ferroan noritic anorthosite clast from Descartes breccia 67215: Clues to the age, origin, structure, and impact history of the lunar crust, Meteorit. Planet. Sci., 38, 645-661.

O'Keefe, J. D., and T. J. Ahrens (1993), Planetary cratering mechanics, J. Geophys. Res., 98, 17,011-17,028.

Papike, J. J., G. W. Fowler, and C. K. Shearer (1994), Orthopyroxene as a recorder of lunar crust evolution: An ion microprobe investigation of Mg-suite norites, Am. Mineral., 79, 796-800.
Papike, J. J., G. W. Fowler, and C. K. Shearer (1996), Ion microprobe investigation of plagioclase and orthopyroxene from lunar Mg-suite norites: Implications for calculating parental melt REE concentrations and for assessing post crystallization REE redistribution, Geochim. Cosmochim. Acta, 60, 3967-3978, doi:10.1016/0016-7037(96)00212-8.

Paquin, R. A. (Ed.) (1995), Properties of Metals, McGraw-Hill, New York.

Pieters, C. M. (1986), Composition of the lunar highland crust from nearinfrared spectroscopy, Rev. Geophys., 24, 557-578, doi:10.1029/ RG024i003p00557.

Pieters, C. M., S. Tompkins, J. W. Head, and P. C. Hess (1997), Mineralogy of the mafic anomaly in the South Pole-Aitken basin: Implication for excavation of the lunar mantle, Geophys. Res. Lett., 24, 1903-1906, doi:10.1029/97GL01718.

Pieters, C. M., J. W. Head, L. Gaddis, B. Jolliff, and M. Duke (2001), Rock types of South Pole-Aitken basin and extent of basaltic volcanism, J. Geophys. Res., 106, 28,001-28,022, doi:10.1029/2000JE001414.

Reid, A. M., A. R. Duncan, and S. H. Richardson (1977), In search of LKFM, Proc. Lunar Sci. Conf., 8th, 2321-2338.

Roddy, D. J. (1977), Large-scale impact and explosion craters: Comparisons of morphological and structural analogs, in Impacts and Explosion Cratering, edited by D. J. Roddy et al., pp. 815-841, Pergamon, New York.

Ryder, G., and J. A. Wood (1977), Serenitatis and Imbrium impact melts: Implications for large-scale layering in the lunar crust, Proc. Lunar Planet. Sci. Conf., 8th, 655-668.

Shervais, J. W., and J. J. McGee (1998a), Ion and electron microprobe study of troctolites, norite, and anorthosites from Apollo 14: Evidence for urKREEP assimilation during petrogenesis of Apollo $14 \mathrm{Mg}$-suite rocks, Geochim. Cosmochim. Acta, 62, 3009-3023, doi:10.1016/S00167037(98)00195-1.

Shervais, J. W., and J. J. McGee (1998b), KREEP in the western lunar highlands: Ion and electron microprobe study of alkali suite anorthosites and norites from Apollo 12 and 14, Am. Mineral., 84, 806-820.

Smith, J. V., A. T. Anderson, R. C. Newton, E. J. Olsen, P. J. Wyllie, A. V. Crewe, M. S. Isaacson, and D. Johnson (1970), Petrologic history of the Moon inferred from petrography, mineralogy, and petrogenesis of Apollo 11 rocks, in Proceedings of the Apollo 11 Lunar Science Conference, pp. 897-925, Pergamon, New York.

Solomon, S. C., and J. W. Head (1980), Lunar mascon basins: Lava filling, tectonics, and evolution of the lithosphere, Rev. Geophys., 18, 107-141, doi:10.1029/RG018i001p00107.

Spudis, P. D., and P. A. Davis (1986), A chemical and petrologic model of the lunar crust and implications for lunar crustal origin, Proc. Lunar Planet. Sci. Conf., 17th, Part 1, J. Geophys. Res., 91, suppl., E84E90, doi:10.1029/JB091iB13p00E84.

Spudis, P. D., B. R. Hawke, and P. Lucey (1984), Composition of Orientale Basin deposits and implications for the lunar basin-forming process, Proc. Lunar Planet. Sci. Conf., 15th, Part 1, J. Geophys. Res., 89, suppl., C197-C210, doi:10.1029/JB089iS01p0C197.

Stöffler, D., H. D. Knöll, U. G. B. Marvin, C. H. Simonds, and P. H. Warren (1980), Recommended classification and nomenclature of lunar highland rocks-a committee report, in Proceedings of the Conference on the Lunar Highlands Crust, Houston, Texas, November 14-16, 1979 , pp. 51-70, Pergamon, New York.

Toksöz, M. N., F. Press, A. Dainty, K. Anderson, G. Latham, M. Ewing, J. Dorman, D. Lammlein, G. Sutton, and F. Duennebier (1972), Structure, composition, and properties of lunar crust, Proc. Lunar Sci. Conf., $3 r d, 2527-2544$

Tompkins, S., and C. M. Pieters (1999), Mineralogy of the lunar crust: Results from Clementine, Meteorit. Planet. Sci., 34, 25-41.

Warner, J. L., C. H. Simonds, and W. C. Phinney (1976), Genetic distinction between anorthosites and Mg-rich plutonic rocks, Proc. Lunar Sci. Conf., 8th, 2215-2235

Warner, J. L., C. H. Simonds, P. E. McGee, and A. Cochran (1978), Luna 24: Lateral heterogeneity in the lunar crust, in Mare Crisium: The View From Luna 24, edited by R. B. Merrill and J. J. Papike, pp. 229-244, Pergamon, New York.

Warren, P. H. (1979), Certain pristine nonmare rocks formed as cumulates from the magma ocean (but many others did not), in Proceedings of the Conference on the Lunar Highlands Crust, Houston, Texas, November 14-16, 1979, pp. 192-194, Pergamon, New York.

Warren, P. H. (1986), Anorthosite assimilation and the origin of the $\mathrm{Mg} / \mathrm{Fe}-$ related bimodality of pristine moon rocks: Support for the magmasphere hypothesis, Proc. Lunar Planet. Sci. Conf., 16th, Part 2, J. Geophys. Res., 91, suppl., D331-D343.

Warren, P. H. (2005), "New" lunar meteorites: Implications for composition of the global lunar surface, lunar crust, and the bulk Moon, Meteorit Planet. Sci., 40, 477-506.

Warren, P. H., and G. W. Kallemeyn (1984), Pristine Rocks (8th Foray) - Plagiophile Element Ratios, Crustal Genesis, and the Bulk 
Composition of the Moon, J. Geophys. Res., 89, C16-C24, doi:10.1029/ JB089iS01p00C16.

Warren, P. H., and J. T. Wasson (1977), Pristine nonmare rocks and the nature of the lunar crust, Proc. Lunar Sci. Conf., 8th, 2215-2235.

Warren, P. H., F. Ulff-Moller, and G. W. Kallemeyn (2005), "New" lunar meteorites: Impact melt and regolith breccias and large-scale heterogeneities of the upper lunar crust, Meteorit. Planet. Sci., 40, 989-1014.

Wieczorek, M. A., and R. J. Phillips (1998), Potential anomalies on a sphere: Applications to the thickness of the lunar crust, J. Geophys. Res., 103, 1715-1724, doi:10.1029/97JE03136.

Wieczorek, M. A., and R. J. Phillips (2000), The "Procellarum KREEP Terrane": Implications for mare volcanism and lunar evolution, J. Geophys. Res., 105, 20,417-20,430, doi:10.1029/1999JE001092.

Wieczorek, M. A., and M. T. Zuber (2001), The composition and origin of the lunar crust: Constraints from central peaks and crustal thickness modeling, Geophys. Res. Lett., 28, 4023-4026, doi:10.1029/ 2001GL012918.
Wieczorek, M. A., et al. (2006), The constitution and structure of the lunar interior, Rev. Mineral. Geochem., 60, 221-364.

Williams, K. K., and M. T. Zuber (1998), Measurement and analysis of lunar basin deposits from Clementine altimetry, Icarus, 131, 107-122, doi:10.1006/icar.1997.5856.

Wood, J. A., J. S. Dickey Jr., U. B. Marvin, and B. N. Powell (1970), Lunar anorthosites and a geophysical model for the Moon, in Proceedings of the Apollo 11 Lunar Science Conference, pp. 965-988, Pergamon, New York.

J. T. S. Cahill and P. G. Lucey, Hawaii Institute of Geophysics and Planetology, University of Hawaii at Mānoa, 1680 East-West Road, POST 602b, Honolulu, HI 96822, USA. (jcahill@higp.hawaii.edu)

M. A. Wieczorek, Institut de Physique du Globe de Paris, 4 Avenue de Neptune, Saint-Maur CEDEX, F-94107, France. 